\title{
Reduced Survival of Motor Neuron (SMN) Protein in Motor Neuronal Progenitors Functions Cell Autonomously to Cause Spinal Muscular Atrophy in Model Mice Expressing the Human Centromeric (SMN2) Gene
}

\author{
Gyu-Hwan Park, ${ }^{1,3}$ Yuka Maeno-Hikichi, ${ }^{4}$ Tomoyuki Awano, ${ }^{1,3}$ Lynn T. Landmesser, ${ }^{4}$ and Umrao R. Monani ${ }^{1,2,3}$ \\ Departments of ${ }^{1}$ Neurology, ${ }^{2}$ Pathology and Cell Biology and ${ }^{3}$ Center for Motor Neuron Biology and Disease, Columbia University Medical Center, New \\ York, New York 10032, and ${ }^{4}$ Department of Neurosciences, Case Western Reserve University School of Medicine, Cleveland, Ohio 44106
}

\begin{abstract}
Spinal muscular atrophy (SMA) is a common $(\sim 1: 6400)$ autosomal recessive neuromuscular disorder caused by a paucity of the survival of motor neuron (SMN) protein. Although widely recognized to cause selective spinal motor neuron loss when deficient, the precise cellular site of action of the SMN protein in SMA remains unclear. In this study we sought to determine the consequences of selectively depleting SMN in the motor neurons of model mice. Depleting but not abolishing the protein in motor neuronal progenitors causes an SMA-like phenotype. Neuromuscular weakness in the model mice is accompanied by peripheral as well as central synaptic defects, electrophysiological abnormalities of the neuromuscular junctions, muscle atrophy, and motor neuron degeneration. However, the disease phenotype is more modest than that observed in mice expressing ubiquitously low levels of the SMN protein, and both symptoms as well as early electrophysiological abnormalities that are readily apparent in neonates were attenuated in an age-dependent manner. We conclude that selective knock-down of SMN in motor neurons is sufficient but may not be necessary to cause a disease phenotype and that targeting these cells will be a requirement of any effective therapeutic strategy. This realization is tempered by the relatively mild SMA phenotype in our model mice, one explanation for which is the presence of normal SMN levels in non-neuronal tissue that serves to modulate disease severity.
\end{abstract}

\section{Introduction}

Proximal spinal muscular atrophy (SMA) is a common, often fatal, infantile neurodegenerative disease caused by mutations in the survival of motor neuron 1 (SMN1) gene (Lefebvre et al., 1995). An almost identical copy gene, $S M N 2$, fails to compensate for the loss of SMN1 because of a translationally silent $\mathrm{C} \rightarrow \mathrm{T}$ nucleotide change in exon 7 (Lorson et al., 1999; Monani et al., 1999) that disrupts the proper splicing of the gene (Cartegni and Krainer, 2002; Kashima and Manley, 2003). SMN2 therefore produces only $\sim 10 \%$ of the full-length functional protein derived from SMN1 and is unable, except in multiple copies, to protect against motor neuron degeneration and the SMA phenotype in affected individuals (Monani, 2005).

The ubiquitous expression of the SMN protein is consistent with an essential role in the biogenesis of U snRNP (small nuclear ribonucleoprotein) particles (Fischer et al., 1997; Liu et al., 1997).

Received April 29, 2010; revised July 2, 2010; accepted July 2, 2010.

This work was funded by National Institutes of Health Grants R01NS19640 (L.T.L.), R01NS057482 and P01NS055923 (U.R.M.), and Department of Defense Grant W81XWH-08-1-0009 (U.R.M.). Additionally, U.R.M. gratefully acknowledges the continued support of the SMA Foundation. We thank K. Nelson and S. Patruni for technical help, Dr. M. Winberg for critically reading this manuscript, and Drs. D.C. De Vivo and C.E. Henderson for advice and suggestions.

Correspondence should be addressed to Umrao R. Monani, College of Physicians and Surgeons, Room 5-422, 630 West 168th Street, New York, NY 10032. E-mail: um2105@columbia.edu.

DOI:10.1523/JNEUROSCI.2208-10.2010

Copyright $\odot 2010$ the authors $\quad 0270-6474 / 10 / 3012005-15 \$ 15.00 / 0$
Indeed, the assembly of these particles, which is a critical step in the proper splicing of pre-mRNAs, is severely compromised in cell as well as animal models of SMA (Gabanella et al., 2007). Yet, in the absence of an identified transcript or group of genes selectively mis-spliced in affected tissues, it is perplexing how the disruption of a housekeeping function results in a largely neuromuscular phenotype. There is also uncertainty about the precise cellular sites of action of the SMN protein. Obvious suspects include skeletal muscle and motor nerves, since the disease phenotype is primarily neuromuscular in origin. In previous attempts to address where wild-type levels of SMN are required to prevent SMA, the protein was selectively knocked out in these and other tissues (Frugier et al., 2000; Cifuentes-Diaz et al., 2001; Vitte et al., 2004). Although muscle as well as neuronal knock-out mice developed phenotypes and eventually succumbed to disease, the results are not surprising. SMN is essential to cell survival, and the knock-out mice were engineered so that the protein was extinguished rather than reduced as it is in the human disease. Moreover, the nerve-targeting experiments abolished SMN indiscriminately in all neurons, including motor and sensory neurons. Using a reverse approach to investigate the tissue specificity of SMN, the protein was transgenically restored to nerve tissue of severely affected model mice (Gavrilina et al., 2008). However, ectopic transgene expression in the mice resulted in an inability to unambiguously determine whether $\mathrm{SMN}$ is required exclusively in nerve, muscle, and/or yet other tissues to prevent 
an SMA phenotype. In more recent work, adeno-associated virus vectors were used to restore SMN globally or specifically to nervous tissue of SMA model mice (Foust et al., 2010; Passini et al., 2010; Valori et al., 2010). Although all three studies reported a pronounced beneficial effect, the extent of benefit differed significantly. Furthermore, a comparison of the results of two of the reports (Foust et al., 2010; Passini et al., 2010) suggests that there may be improved benefit if protein is restored ubiquitously rather than selectively to nerves.

To provide further clarity to the tissue-specific requirements of the SMN protein and refine prior attempts to elucidate its cellular site of action, we chose to selectively deplete but not abolish the protein in motor neurons of healthy mice. Our results indicate that targeted depletion of SMN in motor neuronal progenitors is sufficient to cause a neuromuscular phenotype reminiscent of human SMA, implying that these cells are primarily involved in contributing to disease conditions. However, the disease is less severe than it is in mice expressing ubiquitously low levels of SMN and, interestingly, functional defects obvious in neonates were significantly mitigated in the second postnatal week of life. These results emphasize the absolute need to target motor nerves when designing effective therapies but also underscore the ability of surrounding cell types to modulate, over the course of the disease, the pathology that originates in a cellautonomous manner in the motor neurons.

\section{Materials and Methods}

\section{Transgenic mice}

Olig2-Cre SMA mutants (Olig2-Cre;SMN2;Smn ${ }^{\mathrm{F} 7 /-}$ ) and control littermates (Olig2-Cre;SMN2;Smn ${ }^{\mathrm{F} 7 /+}$ ) were generated as diagrammed in Figure 2 A. Smn ${ }^{\text {F7/F7 }}$ (Jax stock no. 006146) and ROSA26-flox-STOPflox-YFP (Jax stock no. 006148) were obtained from The Jackson Laboratory and genotyped according to protocols on the vendor's website. To detect Cre-mediated recombination at the $S m n^{\mathrm{F7}}$ locus, primers PHR5 and GS8 (Frugier et al., 2000) were used to amplify a $\sim 450$ bp fragment. " $\Delta 7$ " SMA mice were bred and typed as described previously (Le et al., 2005; Kariya et al., 2008). Olig2-Cre transgenic animals were a gift from Dr. T. Jessell, Columbia University (New York, NY) and genotyped using the Cre primers ED-18 (5'-GCTAAGTGCCTT CTCTACACCTGC-3') and ED-19 (5'-GGAAAATGCTTCTGTCCGTTTG-3'). All animal procedures were performed according to institutional guidelines. Males as well as females were included in the study.

\section{Motor behavior analysis}

Righting reflex was used to estimate muscle strength in mutants and control littermates as described previously (Butchbach et al., 2007). Mice were placed on their backs, and latency to turn over and place all four paws on the bench top was recorded. The following arbitrary scores were used to quantify impaired righting ability: 6 for $0-5$ s, 5 for $5-9$ s, 4 for $10-14 \mathrm{~s}, 3$ for $15-19 \mathrm{~s}, 2$ for $20-24 \mathrm{~s}, 1$ for $25-30 \mathrm{~s}$, and 0 if $>30 \mathrm{~s}$. The procedure was repeated thrice for each subject, and the mean was designated the righting ability score. Body weight was measured at the same time. Spontaneous locomotive activity was monitored using the OptoVarimex 4 Auto-Track system (Columbus Instruments). Mice were placed in an arena equipped with infrared photobeam detectors. Beam breaks were converted to locomotive parameters using the software provided by the manufacturer (Columbus Instruments). Activity was recorded between postnatal day (PND) 90 and PND120 for $60 \mathrm{~min}$ following a $30 \mathrm{~min}$ period of adaptation.

\section{Western blot analysis}

SMN protein levels in PND30 animals were determined by Western blot analysis using standard procedures described previously (Monani et al., 2000). SMN (1:10,000; BD Biosciences) and $\alpha$-tubulin (1:5000; SigmaAldrich) monoclonal antibodies were visualized using the ECL Detection kit (RPN 2109; GE Healthcare).

\section{Motor neuron counts and muscle histology}

Spinal cord tissue for motor neuron counts and the analysis of cell-type specificity of the Olig2-Cre driver was extracted, with roots intact, following transcardial perfusion of mice with $4 \%$ paraformaldehyde (PFA) dissolved in $1 \times$ PBS. Proximal (triceps) and distal (gastrocnemius) muscles were obtained simultaneously to assess neuromuscular pathology. All tissue was postfixed in 4\% PFA ( $2 \mathrm{~h}$ ), cryoprotected in 30\% sucrose $(24 \mathrm{~h})$, embedded in Tissue-Tek OCT (Fisher Scientific), and flash frozen for cryostat sections. Ten- to twelve-micrometer-thick muscle sections, cut in a transverse orientation, were stained with hematoxylin and eosin (H\&E; Sigma-Aldrich) to examine fiber morphology and determine fiber numbers as described previously (Monani et al., 2003). Fiber size was determined following image acquisition and using SPOT version 4.5 software (Diagnostic Instruments) or the MetaMorph Imaging System (Molecular Devices). Semitendinosus muscle histology was carried out immediately following functional analyses. Tissue was fixed in 3.7\% PFA (30 min at room temperature), cryoprotected, embedded, and sectioned as described above. In addition to preparing transverse sections, $50 \mu \mathrm{m}$ longitudinal sections were cut to examine neuromuscular junctions (NMJs) (see below). To investigate cell-type specificity of Olig2-Cre, $20-\mu \mathrm{m}$-thick sections from the thoracic spinal cord were cut, blocked in blocking solution (3\% normal serum, $1 \%$ BSA, and $0.3 \%$ Triton X-100 in PBS) for $1 \mathrm{~h}$, incubated overnight at $4^{\circ} \mathrm{C}$ with primary antibodies against green fluorescent protein (GFP) (1:1000; Invitrogen) that also detect GFP variants, such as yellow fluorescent protein (YFP) and choline acetyltransferase (ChAT) (1:100; Millipore) for staining of ventral horn motor neuron or N-cadherin (1:1000; Santa Cruz Biotechnology) for staining of dorsal root ganglion (DRG) neurons, and washed before incubating with appropriate fluorescently conjugated secondary antibodies. After further washing, slides were overlaid with mounting media (Vectashield, Vector Laboratories) and imaged on an E80i Nikon microscope equipped with a Spot Flex digital camera (Diagnostic Instruments). A similar staining protocol was used to quantify spinal motor neurons. The cells on sections obtained from the cervical and lumbar enlargements were detected using the ChAT antibody. A $2.5 \mathrm{~mm}$ region of each enlargement was analyzed for the quantification. SMN expression in spinal motor neurons of transgenic mice was assessed by costaining with antibodies against ChAT (see above) and SMN (1:500; BD Biosciences). The protocol was identical to the one described above, except that an additional $1 \mathrm{~h}$ blocking step using M.O.M. blocker (Vector Laboratories) was included to prevent the secondary antibody from binding to nonspecific mouse antigens.

\section{Central and peripheral synapse immunohistochemistry}

NMJ analysis was carried out on whole muscle, which was fixed and permeabilized for $5 \mathrm{~min}$ in 100\% methanol and incubated with 3\% BSA and $1 \%$ Triton X-100 in PBS. Tissue was then incubated with antineurofilament (NF) antibody (1:1000; Millipore) for $48 \mathrm{~h}$ at $4^{\circ} \mathrm{C}$, washed with PBS-Tween, and incubated for $24 \mathrm{~h}$ at $4^{\circ} \mathrm{C}$ with rhodamine- $\alpha$ bungarotoxin $(\alpha$-BT) $(1: 1000$; Invitrogen $)$ and Alexa Fluor 488 antirabbit IgG (1:1000; Invitrogen). After washing in PBS-Tween, muscles were teased to separate individual fibers before mounting in Vectashield (Vector Laboratories). NMJs were imaged on a laser scanning confocal microscope (Bio-Rad Laboratories) under identical exposure and gain. Terminal arborization was quantified by counting the total number of terminal arbors, which are defined as NF-positive branches twice the length of the width of branches they arose from. The extent of NF accumulation was assessed by measuring the intensity of NF-stained pixels in a predefined area of the largest terminal arbor of an NMJ. Postsynaptic structural complexity was determined by the number of perforations per motor end plate. Pretzel-like NMJs were defined as end plates with at least three perforations, and plaque-like NMJs were defined as those with two or fewer perforations. All NMJs consisting of at least three discrete patches of acetylcholine receptor (AChR) clusters were deemed "fragmented." NMJs of the semintendinosus muscle were examined in $50 \mu \mathrm{m}$ longitudinal sections from tissue fixed in 3.7\% PFA immediately following electrophysiology. After permeabilization and blocking (2\% BSA, $0.3 \%$ Triton X-100 in PBS for $30 \mathrm{~min}$ at room temperature) to prevent nonspecific binding, the sections were incubated overnight $\left(4^{\circ} \mathrm{C}\right)$ in 5 
$\mu \mathrm{g} / \mathrm{ml}$ anti-synaptic vesicle protein 2 (SV2) antibody (Developmental Studies Hybridoma Bank, Iowa City, IA), washed, and then incubated for a further $2 \mathrm{~h}$ with FITC-conjugated goat anti-mouse IgG (1:200; Invitrogen) and rhodamine- $\alpha$-BT (1:500; Invitrogen). All images were captured either by confocal microscopy and analyzed using NIH ImageJ software or by a BX51WI Olympus microscope (Olympus) equipped with a Retiga EXi charge-coupled device camera (QImaging), and staining intensity was quantified with the MetaMorph Imaging System.

\section{Electrophysiology}

Isometric tension measurements. Animals were euthanized at PND8, PND10, and PND12 by $\mathrm{CO}_{2}$ and subsequent decapitation. The semitendinosus muscle, with its nerve supply, was removed and placed in $\mathrm{Ty}$ rode's solution [125 mM NaCl, $5 \mathrm{~mm} \mathrm{KCl}, 24 \mathrm{~mm} \mathrm{NaHCO}_{3}, 1 \mathrm{~mm} \mathrm{MgCl}_{2}$, $10 \mathrm{~mm}$ glucose (Sigma), and $2 \mathrm{~mm} \mathrm{CaCl}_{2}$ ], which was oxygenated by $95 \%$ $\mathrm{O}_{2}$ and $5 \% \mathrm{CO}_{2}$. All chemicals were from Fisher Scientific unless otherwise noted. The proximal tendon of the muscle was carefully pinned in a Sylgard (Dow Corning)-coated recording chamber containing well oxygenated Tyrode's solution maintained at room temperature $\left(20-23^{\circ} \mathrm{C}\right)$. The distal muscle tendon and attached bone were connected to a force transducer (model 360; Harvard Apparatus) by a metal pin. A polyethylene suction electrode was used to stimulate the nerve. A bipolar silver wire electrode was used to stimulate the muscle directly. Because of slight alterations in the position of the pin, the absolute maximal tension generated varied somewhat between experiments. However, for each muscle the tensions in response to nerve and direct muscle stimulation were recorded immediately after each other under the same conditions and repeated several times. Thus, the ratios of tension in response to nerve versus direct muscle stimulation are valid for any experiment, although comparisons of absolute tension measurements between experiments are not. When activating the muscle through the nerve for twitch and tetanus measurements, the stimulus was reduced to below threshold and then slowly increased in strength until maximal tension was achieved. For both mutant and normal muscles at PND8, PND10, and PND12, the tension increased smoothly as stimulus strength was increased. This suggests that the muscles were innervated by roughly the same number of motor neurons and that motor unit sizes were similar, with no motor units making a disproportionately large contribution to overall tension.

Intracellular recordings. Standard sharp electrode intracellular recordings were made from acutely isolated semitendinosus muscles as described previously (Kariya et al., 2008). The semitendinosus muscle preparation was perfused with well oxygenated Tyrode's solution with physiological $(2 \mathrm{~mm}) \mathrm{Ca}^{2+}$ levels to maintain normal in vivo levels of transmitter release. The solution also contained $1-2 \mu \mathrm{M} \mu$-conotoxin GIIIB (Alomone Labs), a specific blocker of muscle voltage-gated sodium channels, to prevent muscle contraction. Sharp glass electrodes were pulled $(10-20 \mathrm{M} \Omega$ ), filled with $3 \mathrm{M} \mathrm{KCl}$, and single muscle fibers were impaled near the motor nerve endings. Potentials were recorded via an intracellular amplifier (model Cyto 721, World Precision Instruments) using Axoscope software (40 kHz sampling rate; Applied Biosystems/ MDS Analytical Technologies). The nerves were stimulated via a suction electrode pulled from polyethylene tubing (PE-190; BD Biosciences) and a monophasic electrical stimuli was generated with SQ38 stimulator and isolated from ground with PSIU6B stimulus isolation unit (both from Grass Technologies).

Quantal content analysis. Quantal content analysis was performed using standard statistics (Colquhoun, 1971). Quantal content $(m)$ in response to single stimuli was calculated by $m=$ average endplate potential (EPP) amplitude/average miniature EPP (mEPP) amplitude. To estimate how many quanta $\left(m_{\mathrm{obs}}\right)$ (where obs is observed) contributed to each EPP recorded in a series of EPPs, the amplitude of each EPP was divided by the average $\mathrm{mEPP}$ amplitude for that ending; EPPs were then classified as a 0 quantal event if $m<0.5$, a 1 quantal event if $0.5<m_{\text {obs }}<1.5$, a 2 quantal event if $1.5<m_{\text {obs }}<2.5$, and so forth. Then the frequency of each " $n$ " quantal event was calculated from the total number of data points $(N)$. If transmitter release statistics conform to a Poisson distribution, the probability of occurrence of $n$ quantal events is given by $P(n)=e^{-m} m^{n} / n !$, and the calculated frequency of each quantal event is given as $N^{\star} P(n)$. The observed frequency and the calculated frequency were subjected to a $\chi^{2}$ test to see if Poisson statistics applied. Based on the Poisson distribution, the proportion of transmission failures observed out of $\mathrm{N}$ stimuli can also be used to estimate quantal content by $\mathrm{m}=\ln$ $N / f$, where $N$ is the number of stimuli and $f$ the number of failures or 0 quanta events.

Quantification of asynchronous release. Asynchronous release was observed at both wild-type and mutant junctions and became greater with increasing stimulus frequency and toward the ends of trains. When asynchronous release was extensive, it was not possible to resolve individual events. Therefore, to compare the extent of asynchronous release we counted the number of EPPs in each $1 \mathrm{~s}$ train that had one or more quantal events/mepps closely following them or riding on their falling phase.

\section{Statistics}

Kaplan-Meier survival curves were compared using the log-rank test equivalent to the Mantel-Haenszel test. To compare means for statistical difference, the unpaired 2-tailed Student's $t$ test or one-way ANOVA followed by Bonferroni's multiple post hoc comparison, where indicated, were employed. Data in the manuscript are represented as mean \pm SEM unless otherwise indicated. All statistical analyses were performed with GraphPad Prism version 4.0 (GraphPad Software). Values of $p<0.05$ were considered significant.

\section{Results}

\section{Olig2-Cre drives recombination of an inducible Smn allele selectively in nervous tissue and is expressed at high levels in spinal motor neurons}

To investigate the tissue specificity of the SMN protein, we used a floxed $\mathrm{Smn}\left(\mathrm{S} m n^{\mathrm{F} 7}\right)$ inducible knock-out allele that is inactivated upon Cre-mediated recombination (Miniou et al., 1999). To inactivate the allele in motor nerves, we initially considered using an NSE-Cre transgenic line in which the expression of Cre recombinase is driven by regulatory elements of the rat neuronspecific enolase (NSE) gene (Frugier et al., 2000). However, the NSE gene expresses pan-neuronally, and the particular line we considered, similar to other NSE-Cre transgenes (Kwon et al., 2006), expresses Cre at low levels outside the nervous system as well. We therefore chose to use an Olig2-Cre transgenic line in which a Cre cassette is knocked into the locus of the motor neuronal progenitor expressing Olig2 gene (Dessaud et al., 2007; Novitch et al., 2001). The endogenous Olig2 gene is expressed at embryonic day 9.5 (E9.5) in the mouse ventral spinal cord (Zhou et al., 2000), and Cre expression from the Olig2-Cre deleter line is observed as early as E10.5 (Dessaud et al., 2007). To ascertain the tissue specificity of Cre-mediated recombination using this transgenic line, we bred the mice to animals harboring the floxed Smn inducible allele and selected double transgenic (Olig2-Cre; $\mathrm{Smn}{ }^{\mathrm{F} 7 /+}$ ) mice for analysis. PCR to detect Cre-mediated recombination of the $S m n^{F 7}$ allele in a wide panel of tissue types indicated that inactivation of the allele was restricted to nervous (brain and spinal cord) tissue (Fig. $1 \mathrm{~A}$ ). Importantly, no recombination was detected in skeletal muscle tissue of the double transgenic mice.

To further characterize the cell-type specificity of the Olig2Cre transgenic line and determine whether Cre expression is restricted to the large motor neurons of the ventral horn of the spinal cord or is pan-neuronal, we bred the mice to ROSA26flox-STOP-flox-YFP reporter animals (Srinivas et al., 2001). Spinal cord sections from ROSA26YFP mice harboring the Olig2-Cre transgene were prepared and examined for the presence of YFP fluorescence. Our results indicate that large ChATpositive neurons of the ventral horn also express YFP while sensory neurons of the DRG do not (Fig. $1 B$ ). We estimated that $\sim 98 \%$ of ChAT-positive cells $(N=887$ cells; $n=3$ mice) coex- 
pressed YFP over the length of the spinal cord, indicative of the efficiency of Olig2Cre mediated recombination. YFP-expressing cells lying outside the ventral horn are likely oligodendrocytes, as Olig2 is known to function sequentially in motor neuron and oligodendrocyte fate specification. $\mathrm{Nev}$ ertheless, our findings demonstrate that Olig2-Cre-mediated recombination is not only specific to nervous tissue but is also confined, among neurons, to spinal motor and not sensory neurons.

\section{Depletion of SMN in motor neuron progenitors is sufficient to cause an SMA phenotype}

Having confirmed that Cre expression in the Olig2-Cre transgenic line is restricted to the nervous system and effects efficient recombination in spinal motor but not sensory neurons of the DRG, we proceeded to determine the phenotypic effect of knocking down SMN to disease state levels in anterior horn cells. In a previous study, Cre expression in nervous tissue resulted in complete knock-out of SMN protein in targeted cells because of the specific strategy that was used. Such an outcome is expected to be lethal to those cells in which recombination of the inducible Smn allele occurs and is never observed in human SMA, which is characterized by constant low levels of the SMN protein. To ensure that we depleted but did not abolish SMN in motor neuronal cells, an SMN2 transgene (Monani et al., 2000) was introduced into the genetic background of all mice subsequently derived for this study (Fig. $2 \mathrm{~A}$ ). To minimize the number of recombination events required to bring about the depletion of SMN protein in motor neurons to disease-relevant levels, we also introduced a null murine Smn allele (Schrank et al., 1997) into our genetic crosses. This allowed us to generate heterozygotes with a floxed Smn allele on one chromosome and the null allele $\left(S m n^{\mathrm{F} 7 /-}\right)$ on its homolog. Smn ${ }^{\mathrm{F} 7 /-}$ mice coexpressing Olig2-Cre and homozygous for SMN2 (Olig2-Cre;SMN2 ${ }^{+/+} ; \mathrm{Smn}^{\mathrm{F} 71-}$ ), known hereafter as Olig2-Cre SMA mutants, were obtained with the expected frequency of $12.5 \%$ and were indistinguishable from control (Olig2$\mathrm{Cre} ; \mathrm{SMN}^{+/+} ; \mathrm{Smn}^{\mathrm{F} 7 /+}$ ) littermates at birth. However, by PND2 a significant difference in weight between mutants and control littermates appeared (control, $2.38 \pm 0.07 \mathrm{~g}$; mutant, $2.02 \pm$ $0.04 \mathrm{~g} ; n \geq 10, p<0.01, t$ test), and this difference remained for the duration of the animals' lives (Fig. $2 B$ ).

Considering the modest $(\sim 15 \%)$ initial difference in body weight, mutants were noticeably weak at PND2 based upon an impaired righting ability when the animals were turned over onto their backs. The weakness was still obvious at PND7 (supplemental video 1, available at www.jneurosci.org as supplemental material). However, quite remarkably, the impaired righting reflex
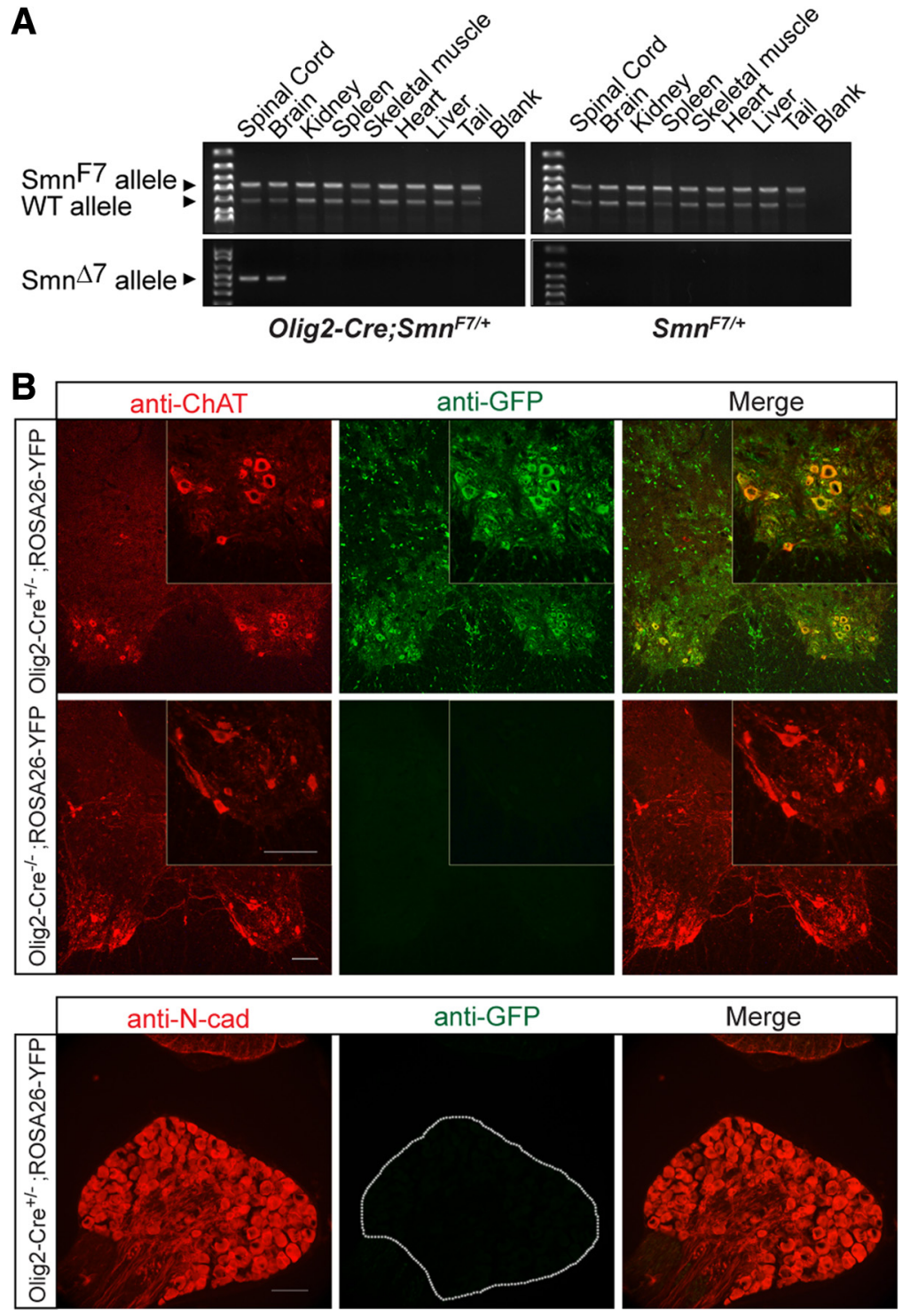

Figure 1. Specificity of Olig2-Cre driven $S m n^{\mathrm{F} 7}$ recombination in nervous tissue. A, Primers specific for the $S m n^{\Delta 7}$ allele detect the recombination event in genomic DNA isolated from spinal cord and brain tissue alone of adult (PND30) Olig2-Cre; $\mathrm{Sm}^{\mathrm{F} 7 /+}$ but not $S \mathrm{mn}{ }^{\mathrm{F} / \mathrm{+}}$ mice. The presence of bands corresponding to the $\mathrm{Sm} n^{\mathrm{F7}}$ allele in nervous tissue of the double transgenics is reflective (n) in ChAT-positive ventral horn motor neurons of Olig2-Cre expressing ROSA26-flox-STOP-flox-YFP mice is evidence of strong expression of Cre-recombinase in these cells. Absence of detectable GFP fluorescence in the neural cadherin-expressing DRG sensory neurons of the mice indicates that Olig2-Cre expression is not pan-neuronal. ROSA26-flox-STOP-flox-YFP mice lacking the Olig2-Cre transgene fail to express GFP fluorescence in ventral horn cells. Scale bars, $100 \mu \mathrm{m}$.

gradually subsided so that by the end of the second week of life there was little difference between affected animals and littermate controls (Fig. 2C). In sharp contrast, symptoms of the disease in $\Delta 7 \mathrm{SMA}\left(\mathrm{SMN} 2^{+/+} ; \mathrm{SMN} \Delta 7^{+/+} ; S m n^{-/-}\right)$mice expressing ubiquitously low levels of SMN protein become inexorably worse with age and muscle weakness, as assessed by impaired righting, and remain significant until death at $\sim$ PND13 (Fig. $2 C, D$ ) (Le et al., 2005). In keeping with the gradual attenuation of the severe weakness of Olig2-Cre SMA neonates, a majority $(\sim 70 \%)$ of mutants survived to $\sim 12$ months of age compared to $100 \%$ of control littermates and $0 \%$ of $\Delta 7$ SMA mutants expressing ubiquitously low SMN (Fig. 2 D). Still, even as adults, Olig2-Cre SMA mutants were clearly distinguishable from littermate controls based on size, reduced muscle mass (supplemental Fig. S1, available at www.jneurosci.org as supplemental material), and in 

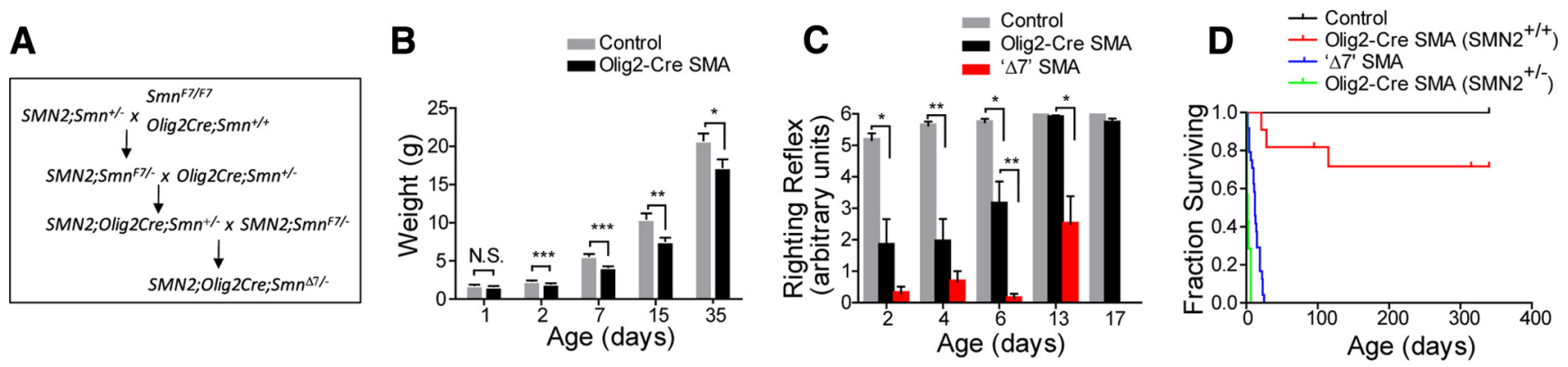

E

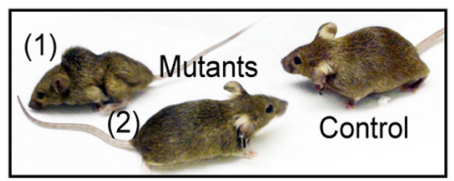

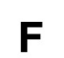

$\mathbf{F}$

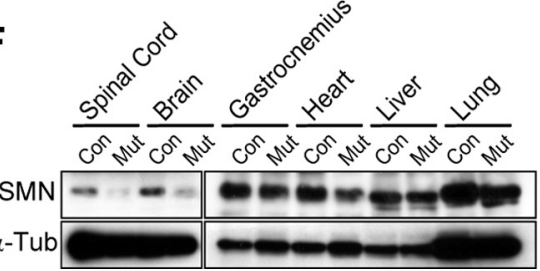

G

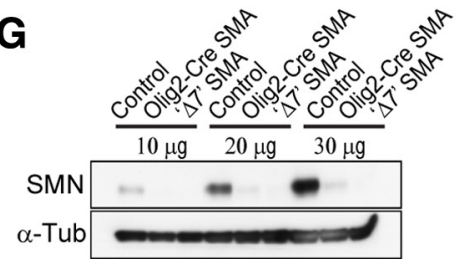

Figure 2. Olig2-Cre SMA mutants express low SMN protein in nervous tissue and exhibit a neuromuscular phenotype. $\boldsymbol{A}$, Genetic crosses to generate 0lig2-Cre SMA mutant mice. $\boldsymbol{B}$, A weight difference becomes apparent in 0lig2-Cre SMA mutants at PND2 and remains significant $\left({ }^{*} p<0.05 ;{ }^{* *} p<0.01 ;{ }^{* * *} p<0.001\right.$ ) into adulthood; $n \geq 10$ for each genotype. $C$, Early and severe neuromuscular weakness in 0lig2-Cre SMA mutants is mitigated in an age-dependent manner, whereas the phenotype remains obvious as the disease progresses in $\triangle 7$ SMA mouse mutants and is considerably worse (mean difference, $3.001, p<0.001$, one-way ANOVA) than the former cohort at PND6; $n \geq 12$ for each genotype. $\boldsymbol{D}$, An increase in disease severity of $\Delta 7$ SMA mutants expressing ubiquitously low SMN as compared to Olig2-Cre SMA mice selectively depleted for protein in nervous tissue. Kaplan-Meier survival curves, censored at PND340, are significantly different between the two mutant groups (log-rank test, $\chi^{2}=26.09, p<0.0001, n \geq 10$ for each genotype). Additionally, Olig2-Cre SMA mutants $(n=11)$ hemizygous for SMN2 have a significantly reduced survival (mean survival, $1.81 \pm 0.7 \mathrm{~d}$ ) compared to Olig2-Cre mutants homozygous for the transgene. Note: ${ }^{*} p<0.01 ;{ }^{* *} p<0.001$. E, Gross phenotype of Olig2-Cre SMA mutants displaying a relatively severe (1) and a more mild (2) form of neuromuscular disease. Severe mutants often display a prominent kyphosis (arrow) of the spine. $F$, Severe and selective reduction of SMN protein in nervous tissue of Olig2-Cre SMA mutants (Mut) and control (Con) littermates. $\alpha$-Tub, $\alpha$-Tubulin. G, Estimation of SMN in spinal cord extracts (10, 20, and 30 $\mu \mathrm{g}$ ) of PND15 $\Delta 7$ SMA, Olig2-Cre SMA, and control animals indicates a significant depletion of protein in the mutants. As expected, selective depletion in motor neuronal progenitors results in greater levels in 0lig2-Cre

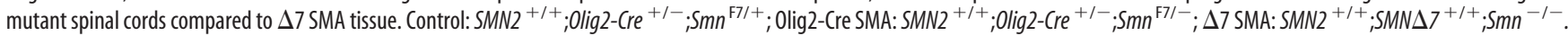

some cases an obvious kyphosis of the spine (Fig. 2E). In addition, and despite a mitigation of the impaired righting ability, mature Olig2-Cre SMA mutants continued to display significant weakness as assessed by grip strength (data not shown) and the open field assay (distance traveled in $60 \mathrm{~min}$ : control, $7225 \pm 378$ cm; mutant, $4771 \pm 226 \mathrm{~cm} ; n \geq 4$ in each case, $p<0.01$, $t$ test). Interestingly, Olig2-Cre SMA mutants hemizygous for the SMN2 transgene were much more severely affected, based on survival, than mice homozygous for the transgene (Fig. 2D). This result, which is consistent with another study (McGovern et al., 2008), suggests that even one additional SMN2 copy can have a profound impact on overall disease phenotype. However, the early lethality of SMN2 hemizygous Olig2-Cre mutants precluded an extensive analysis of these animals, and all subsequent experiments were therefore conducted on SMN2 homozygous mutants (Olig2-Cre;SMN2 ${ }^{+/+} ; \mathrm{Smn}^{\mathrm{FT/}-}$ ).

To assay SMN levels in Olig2-Cre SMA mutants, Western blot analyses were performed on tissue from mutants (Olig2-Cre; $\mathrm{SMN}^{+/+} ; \mathrm{Smn}^{\mathrm{F} 7 /-}$ ) and age-matched controls (Olig2-Cre;SMN2 ${ }^{+/+}$; $\left.S m n^{\mathrm{F} 7 /+}\right)$. As expected, there was a dramatic reduction of protein in spinal cord and brain but not other tissues (Fig. $2 F$ ). Importantly, skeletal muscle from mutant mice expressed wild-type levels of SMN protein, consistent with the absence of any detectable recombination at the floxed $S m n$ locus (Fig. $1 A$ ). A comparative analysis of SMN levels in $\triangle 7 \mathrm{SMA}, S M N 2^{+/+}$Olig2-Cre SMA, and control animals also demonstrated a striking difference between the mutants and control animals, attesting to the efficiency with which Olig2-Cre depletes the protein in spinal cord tissue (Fig. 2G). However, the difference in SMN between the two mutants was more modest with greater levels in the Olig2-Cre SMA mutant. This result would be expected if nonOlig2-Cre-expressing cells such as astrocytes and interneurons in the spinal cords of Olig2-Cre SMA mice continue to express wild- type SMN levels. Collectively, the results described here demonstrate that depletion of SMN in spinal motor neurons is sufficient to cause SMA. However, the early, severe disease phenotype of Olig2-Cre SMA mutants is mitigated somewhat in an agedependent manner, and the rapidly progressing disease that leads to premature death of the $\Delta 7^{\prime}$ SMA mice expressing reduced SMN in all tissues is far less evident following selective motor neuronal SMN knockdown. This suggests that non-nervous cell types modulate the overall SMA phenotype either directly by contributing to the disease or indirectly by acting on the motor neurons and hastening their eventual demise.

\section{SMN functions cell autonomously within motor neurons to} cause neurodegeneration, muscle atrophy, and muscle fiber loss

Having established that Olig2-Cre SMA mutants express vastly reduced SMN protein in spinal cord tissue, we sought to investigate its pathological consequences on the neuromuscular system. Quantification of motor neuron numbers in PND7 Olig2-Cre SMA mutants and littermate controls revealed a modest but statistically insignificant reduction in lumbar and cervical motor neurons of affected mice (supplemental Fig. S2, available at www. jneurosci.org as supplemental material). However, by PND40 mutants possessed $\sim 40 \%$ (cervical) and $\sim 25 \%$ (lumbar) fewer motor neurons than control littermates (Fig. $3 A, B$ ). This result provides important evidence in a mammalian system that neurodegeneration in SMA is very likely a cell-autonomous consequence of reduced SMN in motor neuron progenitors and, quite possibly, in the motor neurons that arise from them. The result is also in keeping with the notion that loss of motor neuron cell bodies in the spinal cords of model mice and, presumably, patients as well is a relatively late event (Monani et al., 2000). To investigate levels of SMN expression in the remaining motor neu- 
rons, spinal cord sections were dual labeled with anti-SMN and anti-ChAT antibodies. As expected and consistent with the Western blot results, SMN expression was significantly reduced in ventral horn cells and SMN staining intensity, similar to that of motor neurons in $\Delta 7$ SMA model mice (Fig. 3C).

Muscle atrophy is a hallmark of human SMA and is also observed in model mice (Le et al., 2005; Monani et al., 2003; Bowerman et al., 2009). It is assumed to be primarily neurogenic in origin. We were able to test this assumption in the Olig2Cre SMA mutants because these animals express reduced SMN in motor neuronal progenitors alone. Proximal (triceps) and distal (gastrocnemius) muscles were obtained from adult mutants and littermate controls, and individual fibers were examined in transverse section. As expected, there were numerous instances of atrophic fibers in affected mice (Fig. 3D), providing the clearest evidence yet that motor neuron loss alone is sufficient to cause muscle atrophy in SMA. Interestingly, a small but significant proportion of fibers also exhibited centrally located nuclei (gastrocnemius: control, $1.26 \pm 0.17$; mutant, $6.67 \pm 0.815, p<0.01$; triceps: control, $1.57 \pm 0.26$; mutant, $15.62 \pm 2.64$, $p<0.05 t$ test, $n \geq 4$ in each case) (Fig. $3 D$ ), suggesting an ongoing regenerative process in mutant muscle. Most intriguingly, despite the presence of atrophic fibers, the average size of mutant fibers was significantly larger than that of controls (Fig. 3E). Considering that total mutant muscle mass was greatly reduced in forelimbs as well as hindlimbs (Fig. S1, available at www.jneurosci.org as supplemental material), we predicted a reduction in fiber numbers in mutant animals. Quantification of fiber numbers in Olig2-Cre SMA mutants indicated that this was indeed the case (gastrocnemius: control, $670 \pm 28$; mutant, $428 \pm 31, p<0.01$; Triceps: control, $703 \pm 37$; mutant, $545 \pm 49, p<$ $0.05, t$ test, $\mathrm{n} \geq 4$ in each case). Since the sizes of control gastrocnemius and triceps are $\sim 30$ and $\sim 24 \%$ larger, respectively than equivalent mutant muscles, the number of fibers per unit area is an underestimation of the real difference between the two sets of animals. Still, this result suggests that reducing SMN in motor neurons either affects the development of appropriate numbers of muscle fibers or results in their gradual loss postnatally. To distinguish between the two possibilities, we quantified fiber numbers of PND7 Olig2-Cre SMA mutants and littermate controls. No significant difference in
A

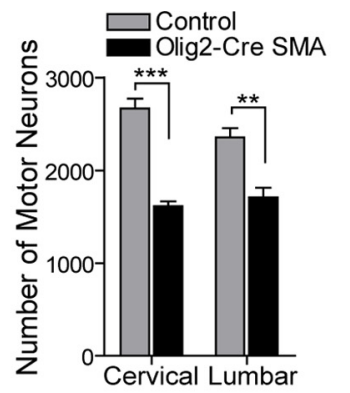

B

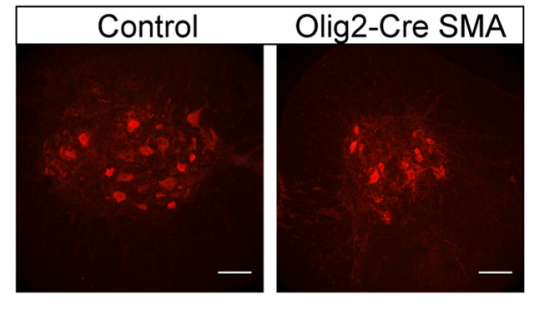

C

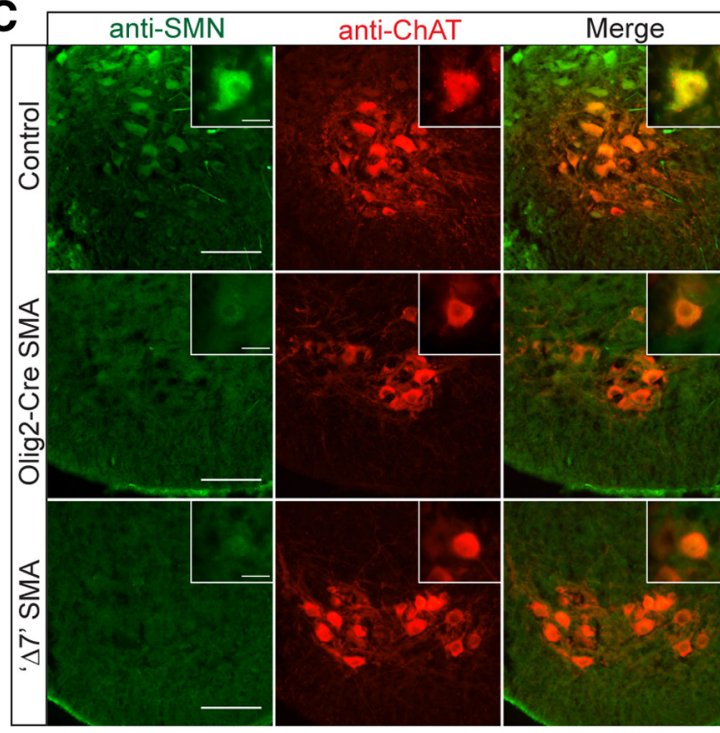

D

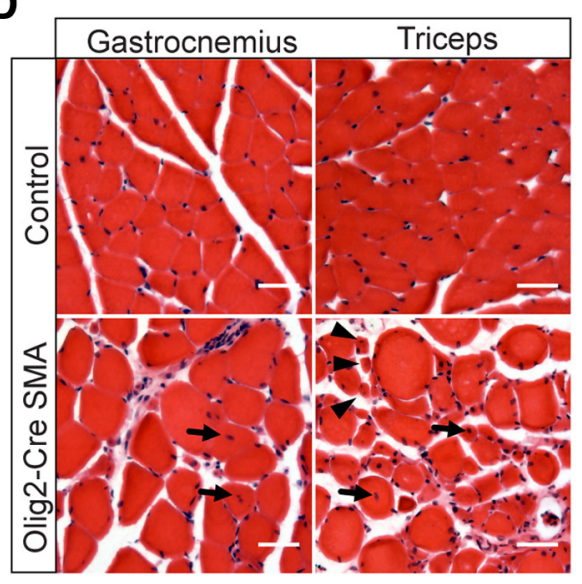

E

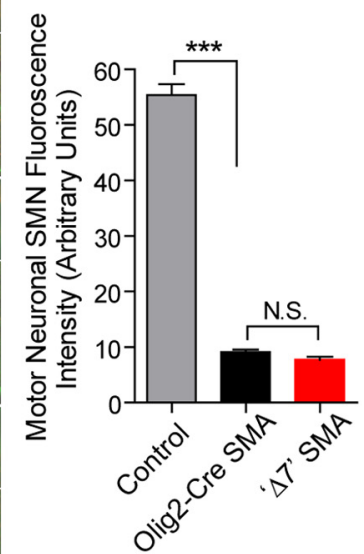

Gastrocnemius

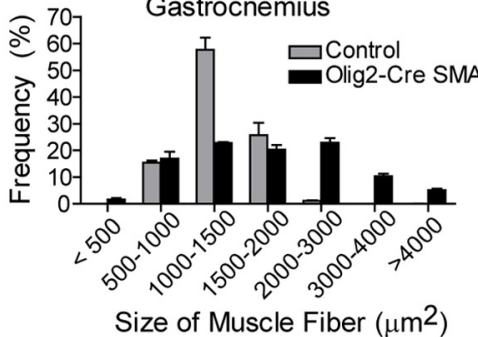

Triceps

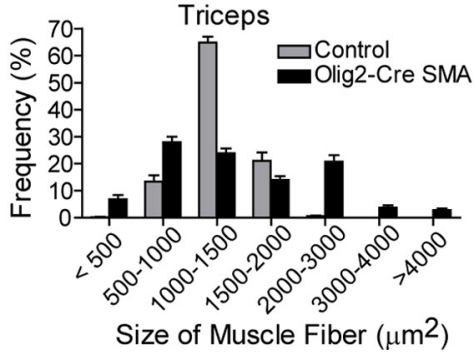

Figure 3. Neuromuscular pathology of Olig2-Cre SMA mutants. $A, B$, Motor neuron loss is significant in the lumbar $\left({ }^{* *} p<0.01, n>5, t\right.$ test) and cervical (*** $p<0.001, n>5, t$ test) spinal cords of mutant animals. C, Surviving (ChAT positive) motor neurons of Olig2-Cre SMA mutants express levels of SMN protein comparable to those of $\triangle 7$ SMA mice and markedly less than cells in control littermates. Insets depict enlarged examples of individual motor neurons in the different mice. Staining intensity of 0lig2-Cre motor neurons was significantly reduced compared to those of control mice but no different from those of $\Delta 7$ SMA mutants ( $n \geq 50$ cells; ${ }^{* * *} p<0.001$ between controls and mutants; ${ }^{\text {N.S. }} p>0.05$ between Olig2-(re and $\Delta 7$ mutants, one-way ANOVA). $\boldsymbol{D}$. Muscle pathology of Olig2-Cre SMA mutants, as assessed in transverse section of H\&E-stained proximal and distal muscles, is characterized by atrophic fibers (arrowheads) centrally located nuclei (arrows). and hypertrophy. $\boldsymbol{E}$, Frequency distribution of the area of individual muscle fibers indicates significant hypertrophy of both proximal and distal muscle groups in 0lig2-Cre SMA mutants ( $n \geq 4$ of each genotype). Scale bars, $\boldsymbol{B}$, $100 \mu \mathrm{m} ; C, 100 \mu \mathrm{m}$, insets, $25 \mu \mathrm{m}, D, 50 \mu \mathrm{m}$. 
numbers was apparent (control triceps, $1035 \pm 11$; mutant triceps, $953 \pm 34, p>0.05, t$ test; $n=3$ ), suggesting that muscle development in mutant mice is normal and that fiber loss occurs between neonatal (PND7) and adult stages of life. Together, the results here demonstrate that SMN functions in a cell-autonomous manner to ensure the health and maintenance of the motor neurons. Depleting motor neuronal SMN not only causes these cells to degenerate but also results in muscle atrophy and loss, which together provide the cellular basis of neuromuscular weakness apparent in Olig2-Cre SMA mutants.

\section{Peripheral as well as central synaptic defects in response to motor neuronal SMN depletion}

We and others have demonstrated previously that defects of the neuromuscular junctions are a defining characteristic of SMA in patients as well as in model mice (Kariya et al., 2008; Kong et al., 2009). To determine whether selective depletion of SMN in motor neuronal progenitors is sufficient to bring about these profound peripheral abnormalities, we examined proximal (triceps) and distal (gastrocnemius) muscle groups from PND7 Olig2-Cre SMA mutants. We showed previously that similarly aged $\Delta 7$ SMA mice exhibit severe NMJ pathology (Kariya et al., 2008). Consistent with the milder phenotype of Olig2-Cre SMA mutants, we did not find evidence of neurofilament aggregates or abnormalities of the acetylcholine receptor clusters at their NMJs (data not shown). However, by 2 weeks of age presynaptic as well as postsynaptic defects were apparent. At the presynapse, NF aggregates had infiltrated nerve terminals and terminal arbors were conspicuously swollen in appearance. Postsynaptically, there was clear evidence of a delayed maturation of AChR clusters into characteristic "pretzels" (Fig. $4 A$ ). In $\Delta 7$ SMA mice it is not possible to evaluate NMJ pathology in fully mature adult mice because of the severity of the disease phenotype and the consequent lethality during the second postnatal week of life. Olig2-Cre SMA mutants, on the other hand, lend themselves to this analysis as they survive to adulthood but express "severe" SMA SMN levels in their motor neurons. We therefore extracted and examined muscle from 5-week-old Olig2-Cre SMA mutants. Our analysis demonstrates that abnormal amounts of NF protein persist in the nerve terminals of both proximal as well as distal muscles. However, in contrast to the poor terminal arborization observed at the NMJs of late stage $\Delta 7$ SMA mice (Kariya et al., 2008), arborization at the synapses of adult Olig2-Cre SMA mutants appeared extensive, and neurofilament protein occupied significantly greater proportions of the NMJs than it did in littermate controls (Fig. $4 B, C$ ). At the postsynapse $>75 \%$ of gastrocnemial AChR clusters had attained a pretzel-like conformation, but more than half of these appeared strikingly fragmented, often stained poorly, and were measurably larger (mutant gastrocnemius, $1052 \pm 78{\mu \mathrm{m}^{2}}^{2}$; control, gastrocnemius, $625 \pm 25 \mu \mathrm{m}^{2}$; $n>3$, $p<0.01, t$ test) than those of control NMJs, likely a consequence of receptor dispersal(Fig. $4 B, D$; Fig. S3, available at www. jneurosci.org as supplemental material). Areas within the fragmented pretzels devoid of AChRs were nevertheless overlaid with NF-positive terminals, giving the appearance of receptor clusters held together by nerve endings. In contrast, wild-type NMJs form "intact" pretzels within which nerve terminals invariably sit atop AChRs (Fig. 4B). Interestingly, mutant AChR clusters of the triceps failed to attain the level of complexity of their gastrocnemial counterparts. Rather, a preponderance of the NMJs in this muscle appeared smaller (mutant triceps, $464 \pm 24 \mu \mathrm{m}^{2}$; control triceps, $745 \pm 62 \mu \mathrm{m}^{2}$; mutant gastrocnemius, $1052 \pm 78 \mu \mathrm{m}^{2}$, one-way ANOVA, $p<0.01$ ), markedly misshapen, and less ma- ture (Fig. $4 B, D$ ) than the neuromuscular synapses of either mutant gastrocnemius or wild-type triceps, suggesting a differential vulnerability of proximal and distal muscles to a reduction of motor neuronal SMN. A summary of these results is presented in tabulated form (Table 1). Several conclusions may be drawn from our analyses of the neuromuscular synapses in the Olig2Cre SMA mutants. First, depleting SMN in motor neuron progenitors, while leaving muscle intact, is sufficient to cause structural abnormalities of both presynaptic as well as postsynaptic specializations. Second, disease progression, based upon NMJ pathology, is not as rapid in mice expressing wild-type SMN in non-nervous tissue as it is in mutants expressing ubiquitously low SMN. Third, despite a severe reduction of motor neuronal SMN protein as the disease progresses, the NMJs do ramify and mature, albeit incompletely. However, AChR clusters eventually regress and become fragmented, most likely because of death and/or severe dysfunction of innervating motor neurons. Finally, in keeping with the selective vulnerability of specific muscle groups in human SMA, NMJs of the proximally located triceps appeared considerably delayed in their maturation relative to those of the distal gastrocnemius, despite the presence of fragmented NMJs in both muscle groups.

Impaired motor function could be a consequence of perturbations not just at the neuromuscular synapse but also at central synapses. For example, loss of function of the ETS transcription factor Er81 disrupts the formation of sensory-motor connections in the spinal cord and results in a severe motor phenotype (Arber et al., 2000). It is clear that peripheral NMJ defects are an important aspect of the pathology that characterizes SMA. To investigate central connectivity in SMA and sensory-motor synapses in particular, we examined the Ia sensory afferent inputs onto motor neurons. To visualize the proprioceptive sensory terminals on motor neurons, spinal cord sections from adult Olig2-Cre SMA mutants and control littermates were costained with antibodies against ChAT and the vesicular glutamate transporter 1 (vGlut1). vGlut 1 has been previously shown to localize to the terminals of Ia afferents on motor neurons (Oliveira et al., 2003). Interestingly, despite a modest increase in total vGlutl puncta in the ventral horns of the Olig2-Cre SMA mice, the number of boutons juxtaposed against ChAT-positive motor neurons in the mutants was greatly reduced (Fig. $4 E$ ). In addition, the mean area of these synaptic boutons was reduced (Fig. $4 E$ ). This suggests a profound alteration in the synaptic coverage of the ventral horn motor neurons by Ia sensory terminals. However, since DRG proprioceptive neurons in the Olig2-Cre SMA mutants express wild-type levels of SMN, these defects are unlikely to be a consequence of perturbations that are intrinsic to the sensory neurons. To further investigate the timing of the appearance of this novel central synaptic defect and because the abnormality would be predicted to occur under conditions of ubiquitously low SMN as well, we examined the spinal cords of PND7 Olig2-Cre SMA mutants, $\Delta 7$ SMA mice, and control littermates. Interestingly, in Olig2-Cre SMA neonates, in addition to a reduction of vGlut1 bouton numbers and their areas on motor neurons, total numbers of puncta quantified in the ventral horn were reduced (Fig. $4 F$, G; supplemental Fig. S4, available at www.jneurosci.org as supplemental material), suggesting an even more acute aberration in the projection of proprioceptive sensory neurons onto ventral horn cells at this early stage of the disease. However, the morphological data are consistent with the partial mitigation of the disease phenotype in an age-dependent manner in the Olig2-Cre SMA mutants. Quantification of motor neuron synaptic coverage in the $\Delta 7$ SMA mice revealed similar aber- 
A
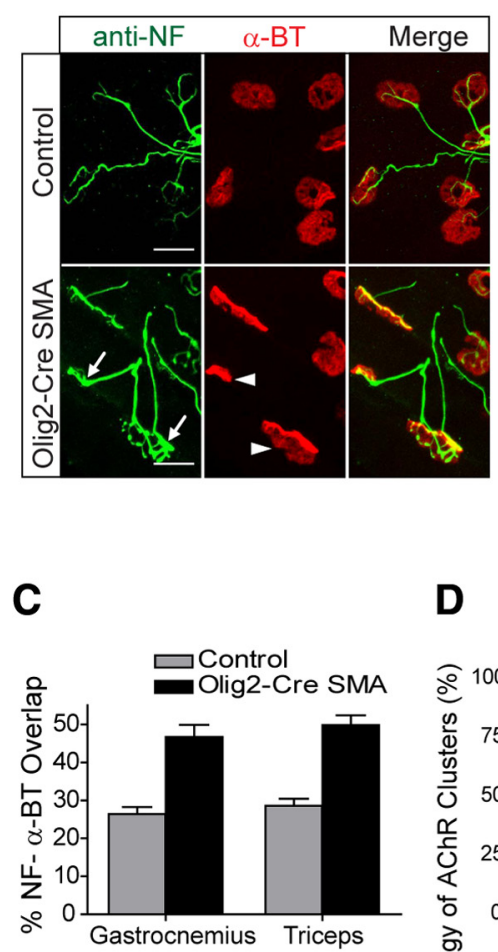

F

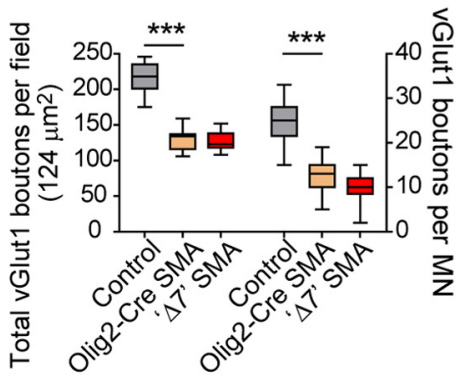

D
NF Accumulation 口Control
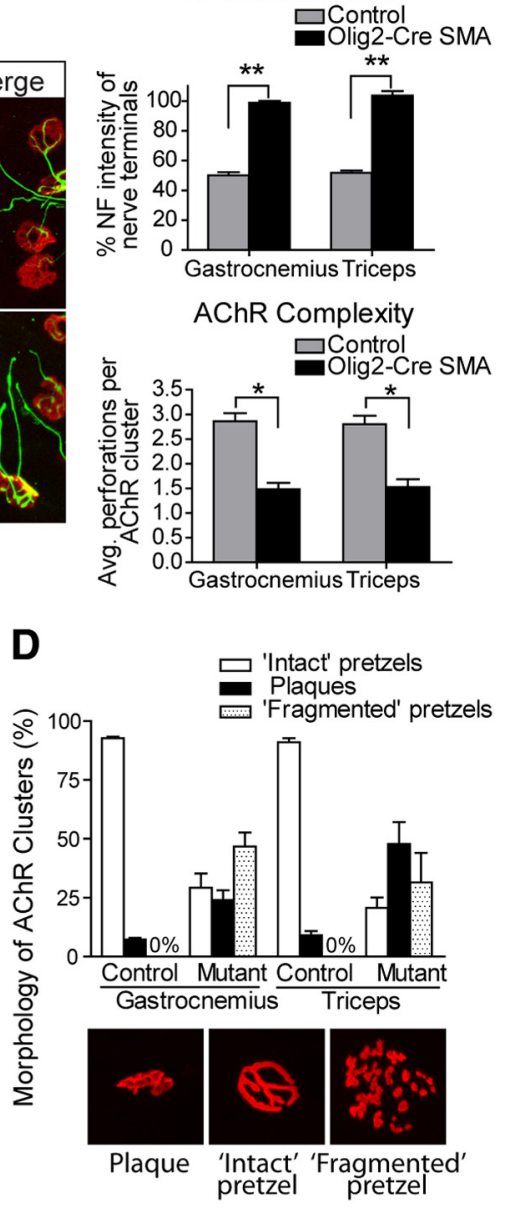

G

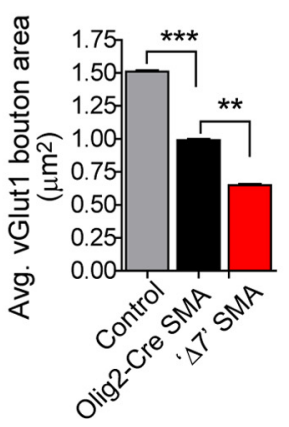

B

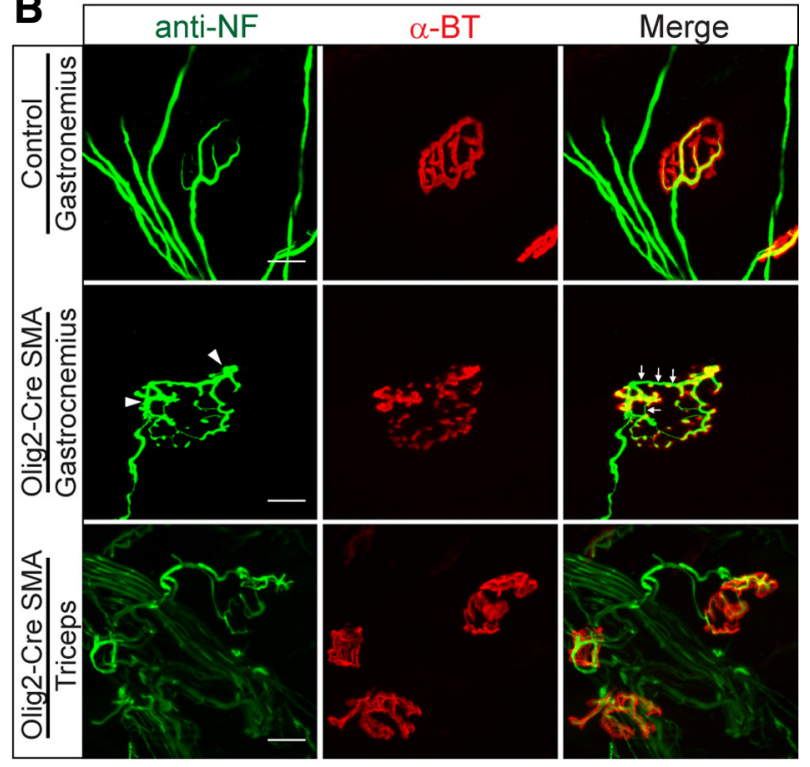

E vGlut1 bouton numbers

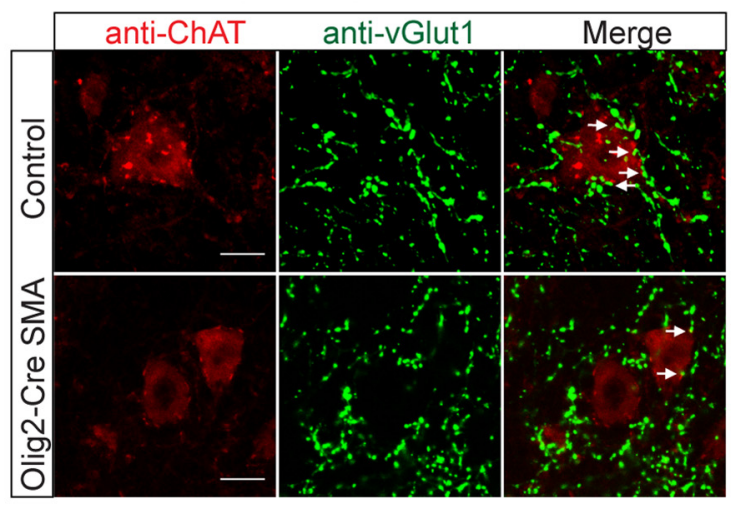

Figure 4. Peripheral and central synaptic defects in Olig2-Cre SMA mutants. $A$, Selectively depleting SMN in motor neurons is sufficient to cause defects of presynaptic as well as postsynaptic specializations of the neuromuscular synapses by 2 weeks of age. Nerve terminals as seen in the triceps appear infiltrated with abnormal levels of NF protein (arrows). On average, NF fluorescence intensity was twice as great in both proximal and distal muscles of mutant animals, while AChR clusters at the postsynapse fail to develop into so-called pretzels (arrowheads). NF accumulation: ${ }^{* *} p<0.01 ; N=3$ mice, $n \geq 40 \mathrm{NMJs}$; AChR complexity: ${ }^{*} p<0.05 ; N=3$ mice, $n \geq 70 \mathrm{NMJs}, t$ test in both instances. $\boldsymbol{B}$, NMJs in distal muscles (gastrocnemius) of adult 0 lig2-Cre SMA mice mature but are predominantly fragmented and continue to display prominent NF swellings (arrowheads) that often fail to overlap with AChRs (arrows). Conversely, NMJs of the proximal triceps appear mostly poorly developed with fewer perforations and NF aggregates. C, Quantification of NF accumulation in presynapses of adult mutant muscle based upon the degree of overlap between NF-positive nerve terminals and $\alpha$-BT staining AChRs, $p<0.01 ; N=3, n \geq 100 \mathrm{NMJs}$, $t$ test. $D$, Quantification of postsynaptic defects in muscle of adult Olig2-Cre SMA mice based upon degree of complexity of AChR clusters. Depicted are examples of plaque-like AChR clusters, intact and fragmented pretzels ( $\geq 100 \mathrm{NMJs}$ were examined). $\boldsymbol{E}$, Motor neuronal SMN depletion perturbs connectivity between proprioceptive DRG neurons and motor neurons in adult Olig2-Cre SMA mutants. The numbers of vGlut1-positive sensory boutons and the areas of these boutons on the motor neurons (see arrows on ChAT positive cells) are significantly reduced ( $p<0.001 ; N=3, n \geq 15$ motor neurons) despite a modest increase in total vGlut1 puncta in mutant spinal cords. $\boldsymbol{F}, \boldsymbol{G}$, Proprioceptive sensory-motor connectivity is similarly perturbed at PND7 in response to selective motor neuronal and ubiquitous SMN depletion and extends to include a reduction of total numbers of $v$ Glut1 puncta in the ventral spinal cord $(\boldsymbol{F})$. Scale bars, $\boldsymbol{B}, 20 \mu \mathrm{m} ; \boldsymbol{E}, 25 \mu \mathrm{m}$.

rations under conditions of ubiquitously low SMN (Fig. $4 F, G)$. Indeed, the abnormality is more severe than that in Olig2-Cre SMA mutants, suggesting that even if the defect originates in the motor neurons, other cell types may modulate the extent of the overall phenotype. In summary, these results suggest that peripheral synapses are not the only ones affected by reduced motor neuronal SMN. Central synapses are also affected, but most likely as a consequence of events that are initiated cell autonomously within the $\alpha$-motor neurons. 
Table 1. Neuromuscular junction defects in adult 0lig2-Cre SMA mutant mice

\begin{tabular}{|c|c|c|c|c|c|}
\hline \multirow[b]{2}{*}{ Muscle type } & \multicolumn{2}{|l|}{ Presynapse } & \multicolumn{3}{|l|}{ Postsynapse } \\
\hline & $\begin{array}{l}\mathrm{NF} \\
\text { aggregates }\end{array}$ & $\begin{array}{l}\text { Arborization } \\
\text { (average terminals/NMJ) }\end{array}$ & $\begin{array}{l}\text { Complexity } \\
\text { (average perforations/NMJ) }\end{array}$ & $\begin{array}{l}\text { AChR cluster size } \\
\left(\mu \mathrm{m}^{2}\right)\end{array}$ & $\begin{array}{l}\text { NMJ morphology } \\
\text { (plaque/pretzel/fragmented pretzel) (\%) }\end{array}$ \\
\hline \multicolumn{6}{|l|}{ Distal } \\
\hline Control gastrocnemius & - & $\begin{array}{l}4.0 \pm 0.1 \\
\{\text { N.S. }\}\end{array}$ & $\begin{array}{l}3.3 \pm 0.7 \\
\{p<0.05\}\end{array}$ & $\begin{array}{l}625 \pm 25 \\
\{p<0.01\}\end{array}$ & $7 / 93 / 0$ \\
\hline Mutant gastrocnemius & + & $5.1 \pm 0.6$ & $1.4 \pm 0.3$ & $1052 \pm 78$ & 24/29/47 \\
\hline \multicolumn{6}{|l|}{ Proximal } \\
\hline Control triceps & - & $\begin{array}{l}4.1 \pm 0.1 \\
\{\text { N.S. }\}\end{array}$ & $\begin{array}{l}2.0 \pm 0.6 \\
\{p<0.05\}\end{array}$ & $\begin{array}{l}745 \pm 62 \\
\{p<0.05\}\end{array}$ & $9 / 91 / 0$ \\
\hline Mutant triceps & + & $4.9 \pm 0.4$ & $1.0 \pm 0.2$ & $464 \pm 24$ & $48 / 21 / 31$ \\
\hline
\end{tabular}

Arborization was assessed by quantifying the total number of individual terminal arbors per endplate. To qualify as an arbor, it had to be at least twice as long as the diameter of the branch it arose from. NMJs were classified into plaques, intact pretzels, and fragmented pretzels as described in Materials and Methods and are represented as percentages.

\section{An age-dependent attenuation of early functional deficits in Olig2-Cre SMA mice}

We and others showed previously that muscle weakness in $\Delta 7$ SMA mice precedes the loss of motor neuron cell bodies in the spinal cord but appears concurrently with distal defects of the motor unit (Kariya et al., 2008; Kong et al., 2009). Our behavioral analyses of the Olig2-Cre SMA mutants were also predictive of early defects of the neuromuscular synapses. Yet, intriguingly, we failed to observe in these mutants the striking NF pathology that characterizes abnormal NMJs of neonatal $\Delta 7$ SMA mice. Furthermore, we were surprised to find that the early severe impairment in righting ability, which in $\Delta 7$ mutants eventually progresses to complete paralysis, gradually subsided by the end of the second week of life of the Olig2-Cre SMA mice (Fig. 2C), following which the animals entered a relatively stable disease state. To investigate the apparent attenuation of early motor dysfunction in the Olig2-Cre SMA mutants, we assessed neuromuscular function electrophysiologically at PND8, when the phenotype was readily apparent, at PND10, and finally at PND12-13, by which time the impairment was no longer obvious. To do so, tension measurements and intracellular recordings were made from the predominantly fast (Rafuse et al., 2000) semitendinosus thigh muscles of mutant and control littermates. Mouse muscle fibers are polyneuronally innervated at birth but become singly innervated by the process of synapse elimination sometime between the first and second postnatal week, depending on the muscle. By PND6 in the trapezius (Colman et al., 1997) and PND8 in the sternomastoid muscle (Balice-Gordon and Lichtman, 1993), only $30 \%$ of the fibers are polyneuronally innervated. By using the method of tension occlusion, the semitendinosus muscle in wild-type mice was shown to exhibit extensive polyneuronal innervations at PND3 and PND4, but none at PND9, PND10, and PND11 (Rafuse et al., 2000) (V. Rafuse and L.T. Landmesser, unpublished observations). Thus, at the start of our physiological experiments at PND8, synapse elimination should be largely complete. However, as muscle fibers continue to grow in diameter, there is a compensatory increase in the size of the junctions and in the mean quantal content, which is required to maintain effective transmission.

A reduction in quantal content has been reported in several different muscles of $\Delta 7$ SMA mutants during the early postnatal period (Kong et al., 2009; Ruiz et al., 2010). However, because of the relatively large safety factor at rodent NMJs (Wood and Slater, 2001), it is not clear whether the reported reductions in quantal content would prevent a sufficient number of muscle fibers from being activated to threshold to contribute to the motor defects detected behaviorally. To address this possibility, we measured muscle tension in response to single stimuli and to $2 \mathrm{~s}$ trains at 10 ,
20, 50, and $100 \mathrm{~Hz}$. Contractions were first evoked by supramaximal stimulation of the muscle nerve. The nerve-evoked twitch and tetanus tension values were then compared to those elicited by direct stimulation of the muscle via bipolar wire electrodes, which should activate most of the muscle fibers. At PND8, maximal tension during nerve-evoked trains occurred at $50 \mathrm{~Hz}$ in both SMA and control mice, with a decline in tension of $20-30 \%$ at $100 \mathrm{~Hz}$. However since a decline of similar amplitude at $100 \mathrm{~Hz}$ also occurred when the muscles were directly stimulated, this must reflect a property of the PND8 muscle and not an inability of the junctions to activate the muscle. At PND8, $100 \mathrm{~Hz}$ nerve stimulation of control muscles was able to evoke $72 \%$ of the tension produced by direct stimulation of the muscle. In contrast, nerve stimulation of the Olig2-Cre SMA mice was only able to produce $34 \%$ of the tension produced by direct muscle stimulation (Fig. $5 A, B$ ). These observations suggest that many of the SMA junctions failed to activate muscle fibers to threshold, which was also seen with $50 \mathrm{~Hz}$ stimulation (nerve/muscle tension ratio of $36 \%$ ). Remarkably, by PND12, $100 \mathrm{~Hz}$ stimulation of the nerve in both the SMA mutant and control littermate was able to activate all of the muscle fibers (Fig. 5B). These results suggest that Olig2-Cre SMA mice are born with or develop early defects in neuromuscular transmission, but that between PND8 and PND12 there is a homeostatic compensation that overcomes these defects. Fatigue during the $100 \mathrm{~Hz} 2 \mathrm{~s}$ trains, defined as the decline in tension from the beginning to the end of the train, was determined to be $10-20 \%$ for PND12 SMA and control with either nerve or direct muscle stimulation. PND8 mutant muscle exhibited slightly more decline in tension (26\%) than at PND12, but as this was seen with both muscle and nerve stimulation (Fig. $5 A$ ), it cannot be caused by deficits in transmission and was modest in any case. Thus, this result suggests that even though nerve stimulation of PND8 mutant muscle is unable to activate the vast majority $(\sim 65 \%)$ of muscle fibers, transmission at the remaining junctions is normal with only modest fatigue even at $100 \mathrm{~Hz}$.

To further characterize synaptic transmission, we carried out intracellular recordings between PND8 and PND12. At PND8 we found that while mEPP frequency did not differ between mutant and control (Olig2-Cre SMA, $1.01 \pm 0.20$ /s; control, $0.81 \pm 0.95$ /s), there was a striking decrease (Fig. $5 C$ ) in the mean quantal content of the SMA junctions compared to controls, 1.35 versus 11.26 , respectively, which likely contributes to the failure of many fibers to be activated to threshold in the mutant. However, at both PND10 and PND12 mutant NMJs the quantal content had significantly increased, 8.85 and 6.13 , respectively, which restored values to (PND10) or toward (PND12) control levels. Interestingly, we found that at all three time points the mean $\mathrm{mEPP}$ amplitude at mutant NMJs was 50-100\% greater than that at 
A

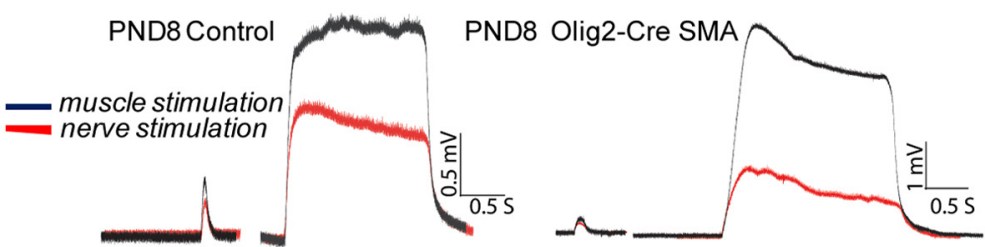

B

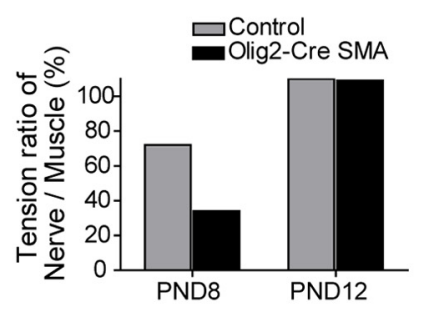

D

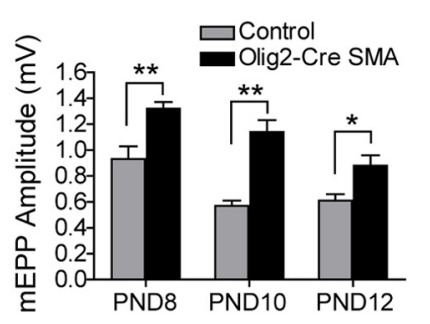

C

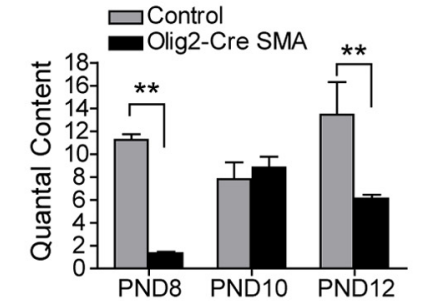

$\mathbf{E}$

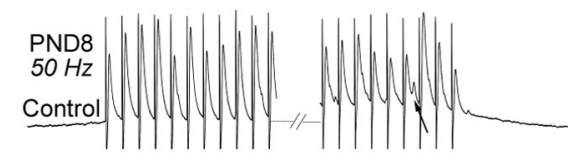

$\mathbf{F}$
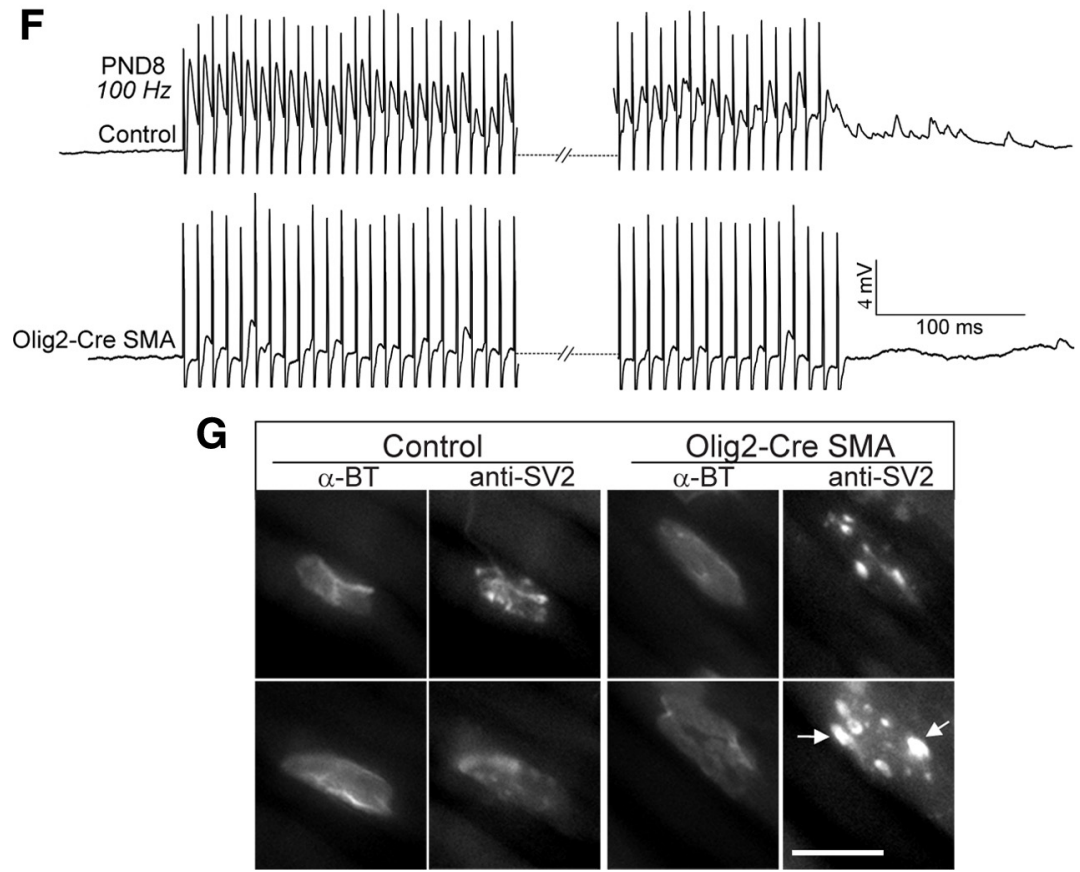

Figure 5. Age-dependent attenuation of neuromuscular transmission deficits in 0lig2-Cre SMA mutants between PND8 and PND12.A, Tension evoked by single stimuli and by $2 \mathrm{~s} 100 \mathrm{~Hz}$ trains. Tension response to nerve stimulation (red trace) was less than that evoked by direct stimulation of the muscle (black trace) in both mutant and control muscles at PND8, but this difference was considerably greater for the SMA mutant muscle. $\boldsymbol{B}$, Tension ratios evoked by nerve versus direct muscle stimulation in response to $100 \mathrm{~Hz}$ train at PND8 and PND12. While nerve stimulation was only able to activate 34\% of the muscle fibers in the PND8 mutant, by PND12 all muscle fibers in mutant and control muscle were activated following $100 \mathrm{~Hz}$ nerve stimulation. C, Quantal content calculated from EPP/mean mEPP amplitudes at PND8, PND10, and PND12. The quantal content at the SMA junctions was dramatically reduced compared to control at PND8, but by PND10 had increased to wild-type values. However, quantal content failed to further increase at mutant junctions as it did at control NMJs and, thus, at PND12 ithad significantly lowervalues. $\left({ }^{* *} p<0.01\right.$, $t$ test).D, Mean mEPP amplitudeat SMA mutant junctions between PND8 and PND12 was significantly greater than at control junctions. ${ }^{*} p<0.05 ;{ }^{* *} p<0.01, t$ test). E, EPP trains in response to $50 \mathrm{~Hz}$ stimulation at mutant and control NMJs. Controls (top trace) exhibited a moderate variation in amplitude and some asynchronous release (arrow), but no transmission failures. Mutant junctions exhibited intermittent transmission failures (asterisk), asynchronous release (arrows), and a greater variation in amplitude. $F$, EPP trains following $100 \mathrm{~Hz}$ stimulation. Control junctions (top trace) exhibited some depression and considerable asynchronous release that was apparent even after the stimulus. However they showed only an occasional transmission failure. The mutant junctions (bottom trace) also exhibited asynchronous

control junctions (Fig. 5D). This would be expected if there had been an increase in the input resistance of the SMA muscle fibers. Alternatively, the amount of acetylcholine per vesicle or the postsynaptic response to a given amount of the neurotransmitter might have increased as a homeostatic response to the reduced efficacy of transmission observed at PND8 (Davis and Goodman, 1998; Wang et al., 2005). Although we did not measure input resistance, we compared mutant and control muscle fiber areas to detect changes that might have resulted in altered input resistance. At PND8, we found a modest but statistically significant decrease in mutant fiber area (Olig2-Cre SMA, $574.2 \pm 1.2 \mu \mathrm{m}^{2}$, $n=225$; control, $754.0 \pm 14.9 \mu \mathrm{m}^{2}, n=$ 299). However, this was insufficient to account for the increased mEPP amplitude. An estimation of AChR density based upon mean pixel intensity following $\alpha$-bungarotoxin immunostaining demonstrated a $\sim 10 \%$ decrease at SMA NMJs (Olig2-Cre SMA, $10844 \pm 322, n=162$; control, $12160 \pm 423, n=122)$. However, since this would have been associated with a decrease in mEPP amplitude rather than an increase, our results suggest either a change in input resistance unrelated to muscle fiber diameter or an increase in the amount of acetylcholine released per vesicle in the SMA mutant mice. The latter has previously been invoked to explain an increase in quantal size in response to activity blockade at mouse NMJs (Wang et al., 2006). At PND10 and PND12 the increase in mEPP size, together with an increase in quantal content, was able to restore EPP amplitudes of mutant NMJs to $\geq 5 \mathrm{mV}$. EPP amplitudes at mutant PND8 NMJs, on the other hand, remained $<1 \mathrm{mV}$. Collectively, this set of results suggest a profound deficiency of neuromuscular transmission at PND8 and a remarkable improvement between PND10 and PND12, which is consistent with a recovery from the severe impairment of motor dysfunction as assessed behaviorally.

In keeping with the greatly reduced quantal content values and an inability to activate adequate fibers during tension

$\leftarrow$

release, but in addition had numerous failures of transmission. G, SV2 and $\alpha$-bungarotoxin immunostaining at PND8 0lig2Cre SMA mutant and control junctions. Postsynaptic AChR clusters were no different in mutant mice. SV2 immunostaining was diffusely distributed in most control endings (bottom) with an occasional endplate showing more punctate staining (top). In contrast, most mutant junctions were characterized by large, intensely staining puncta (arrows) interspersed within regions mostly devoid of SV2 stain (especially see top example). Scale bars, $10 \mu \mathrm{m}$. 
Table 2. Quantification of neurotransmission failures in PND8-12 0lig2-Cre SMA mice

\begin{tabular}{lcrccc}
\hline $\begin{array}{l}\text { Stimulation } \\
\text { frequency }\end{array}$ & \multicolumn{1}{l}{ PND8 } & & \multicolumn{2}{l}{ PND12 } \\
\cline { 2 - 3 } \cline { 5 - 6 } & Control & Mutant & & Control & Mutant \\
\hline Singles & $0 \pm 0$ & $18.15 \pm 5.00$ & & $0 \pm 0$ & $0 \pm 0$ \\
$10 \mathrm{~Hz}$ & $0 \pm 0$ & $10.10 \pm 3.19$ & & $0 \pm 0$ & $0.81 \pm 0.59$ \\
$20 \mathrm{~Hz}$ & $0 \pm 0$ & $9.84 \pm 2.45$ & & $0 \pm 0$ & $1.03 \pm 0.48$ \\
$50 \mathrm{~Hz}$ & $0 \pm 0$ & $8.53 \pm 2.07$ & & $1.2 \pm 1.2$ & $4.51 \pm 4.03$ \\
$100 \mathrm{~Hz}$ & $7.38 \pm 1.84$ & $45.04 \pm 8.11$ & & $43.96 \pm 12.89$ & $39.55 \pm 7.94$ \\
\hline
\end{tabular}

Failures are presented as percentage of the total number of stimuli.

measurement assays, PND8 mutant NMJs also exhibited a significant increase in neurotransmission failures. We observed these both in response to single stimuli and during trains at 10,20, and $50 \mathrm{~Hz}$ (Fig. 5E, bottom trace, asterisk), whereas failures were quite rare at control junctions (Fig. 5E; Table 2). Asynchronous release, which we also quantified (for details, see Materials and Methods), was evident at mutant as well as at control NMJs (Fig. $5 E$, arrows) and, in contrast to results from $\Delta 7$ SMA mice (Ruiz et al., 2010), did not differ significantly between the two cohorts of mice at any of the stimulation frequencies used (control: at $10 \mathrm{~Hz}$ : $1.4 \pm 0.4$; at $20 \mathrm{~Hz}, 4.1 \pm 1.29$; at $50 \mathrm{~Hz}, 20.9 \pm 3.11$; Olig2-Cre SMA: at $10 \mathrm{~Hz}, 2.22 \pm 0.49$; at $20 \mathrm{~Hz}, 6.22 \pm 0.7$; at $50 \mathrm{~Hz}, 24.61 \pm$ 3.61). This suggests that $\mathrm{Ca}^{2+}$ homeostasis in the presynaptic terminals of Olig2-Cre SMA mutants is not altered as has been reported for the levator auris longus and transverse abdominus muscles of $\Delta 7$ SMA mice (Ruiz et al., 2010). At $100 \mathrm{~Hz}$ asynchronous release greatly increased at control junctions, particularly following the train (Fig. $5 F$ ), but disappeared at SMA NMJs undergoing numerous failures, suggesting that during these events there is little $\mathrm{Ca}^{2+}$ entry into the nerve terminals of mutant mice.

Since our analysis of quantal content at SMA junctions indicated such a dramatic reduction and since calculations from EPP: mEPP ratios are not always precise, we reassessed this parameter based upon our repetitive stimulation experiments. When the probability of release and, consequently, quantal content is reduced at adult wild type NMJs by lowering the extracellular $\mathrm{Ca}^{2+}$ concentration, transmitter release statistics conform to a Poisson distribution. We used Poisson statistics to determine that quantal content (ln $N / f ; N$, total number of nerve stimuli; $f$, number of failures) at PND8 mutant NMJs in response to single stimuli and $10 \mathrm{~Hz}$ trains was 1.7. This corresponded well with the value of $\sim 1.4$ obtained from the ratio of EPP:mEPP and confirmed the extent of the neurotransmission deficit in PND8 mutant mice. Importantly, EPP distributions at a given synapse into one, two, or higher quantal events (see Materials and Methods for more details) based on observations also corresponded with what was expected from Poisson statistics, adding confidence to the quantal content calculations. In addition, these results indicate that the failures observed in response to single stimuli are likely to arise because of either a reduction in the probability of release or the number of release sites and thus suggest that additional mechanisms are not required to explain them. In contrast, the large number of failures seen at mutant junctions with $100 \mathrm{~Hz}$ stimulation, as noted below, suggest additional presynaptic defects in transmission. Interestingly, in contrast to single stimuli, mutant junctions stimulated at $10-50 \mathrm{~Hz}$ displayed a decline in the number of failures, suggestive of facilitation that increases the probability of release because of an increase in $\mathrm{Ca}^{2+}$ in the nerve terminal. On the other hand, stimulation at $100 \mathrm{~Hz}$ resulted in a dramatic increase in the number of failures (Fig. 5F; Table 2), reflecting an inability of these mutant junctions to follow at high frequency. Individual junctions exhibited considerable variability, with some having occasional failures throughout the train and others with longer periods during the train without any evoked responses. While PND8 control junctions also exhibited some failures at $100 \mathrm{~Hz}$, these were significantly fewer than at mutant NMJs. Remarkably, by PND12 the SMA mutants had become similar to controls with essentially no failures to single stimuli and with a small number of failures that were not statistically different from control junctions at 10,20, and $50 \mathrm{~Hz}$ (Table 2 ). It is not certain why both control and mutant NMJs display greater numbers of failures at $100 \mathrm{~Hz}$ than control NMJs at PND8, but this could be because of ongoing maturational changes at the synapse that characteristically occur at this stage of mouse development.

Having determined that there are profound neuromuscular transmission defects as assessed at the NMJs of the semitendinosus muscle of PND8 Olig2-Cre SMA mutants, we sought to reassess the presence of morphological correlates. We therefore subjected muscles that had been used for the electrophysiology to immunohistochemical staining procedures. Although we did not find discernible defects of the postsynaptic AChR clusters, we found striking alterations in the distribution of the synaptic vesicle (SV2) protein (Fig. 5G). In particular, SV2 protein appeared localized to numerous intensely staining puncta within the terminals of mutant endplates (Fig. $5 G$, arrows), with some areas devoid of staining, whereas it was diffusely spread over the entire endplate of control animals. This suggests an abnormal localization of synaptic vesicles in Olig2-Cre SMA terminals and a consequent inability of much of the mutant terminal to undergo vesicle exocytosis. The abnormal localization is consistent with what we and others have reported in mice expressing ubiquitously low SMN protein (Kariya et al., 2008; Kong et al., 2009). By PND12, SV2 mislocalization in mutant semitendinosus was no longer evident (Fig. S5, available at www.jneurosci.org as supplemental material), a result once more in keeping with the mitigation of the early behavioral and functional abnormalities observed when SMN is selectively depleted but not abolished from motor neuronal progenitors. In summary, our functional and morphological analyses of early postnatal Olig2-Cre SMA NMJs have demonstrated severe deficits of neuromuscular transmission at PND8 that are consistent with and provide the underlying basis for the profound impairment of motor dysfunction at this stage of the disease. Quite remarkably, the deficits are significantly attenuated as the disease progresses, and this could provide at least a partial explanation of the mitigation of motor dysfunction by 2 weeks of age.

\section{Persistent neuromuscular transmission deficits in adult Olig2-Cre SMA mice}

Despite an attenuation of early neuromuscular transmission defects by PND12 and a concurrent, apparent recovery of motor dysfunction as assessed by righting ability, Olig2-Cre SMA mutants continued to display weakness as adults. Moreover, the mice exhibited clear evidence of neuromuscular pathology (Fig. 3). We therefore extended our functional analysis to the semitendinosus muscle of 3-month-old Olig2-Cre mutant animals. Intracellular recordings indicated an increase in mEPP amplitude (Fig. 6A) despite a decrease in input resistance (control, $25.13 \pm 0.61 \mathrm{M} \Omega$; Olig2-Cre SMA, $20.51 \pm 0.44 \mathrm{M} \Omega ; p<0.01$ ), suggesting that perhaps there was an increase in AChR density in the mutant. However, receptor numbers, based on $\alpha$-BT staining, did not differ significantly between mutant and control NMJs (data not shown). mEPP frequencies tended to be higher at mutant NMJs 
but were not statistically different from those at control endplates (Fig. 6B). Intriguingly, EPPs and consequently quantal content measurements indicated a significant increase in values at mutant junctions (Fig. 6C,D), suggesting that the mechanisms that restore reduced quantal content to near normal levels by PND10-12 eventually overcompensate in adult animals. However, the distribution of quantal content values at adult SMA junctions, which appeared bimodal rather than unimodal (Fig. 6E), suggests that only some NMJs have greater than normal quantal content values while the rest of the population is in the wild-type range. Morphologically, the mutant NMJs appeared very similar to those in the gastrocnemius and triceps that we had examined and did not differ significantly from control junctions with respect to SV2 localization (Fig. S6, available at www.jneurosci.org as supplemental material). Together, these results extend our findings in PND12 Olig2-Cre SMA mice but also point to mechanisms at the mutant NMJ that overcompensate, as the disease progresses, for deficiencies that are apparent early during neonatal stages.

\section{Discussion}

Considering the ubiquitous requirement of the SMN protein, there are two questions that continue to perplex scientists engaged in studying SMA. (1) Why do motor neurons selectively degenerate in the human disease? (2) What is the primary site of action of the SMN protein to cause this selective cell loss? In this study, we took advantage of Cre-lox technology to develop novel model mice that express reduced SMN protein specifically in motor neuron progenitors and thus allow us to address the second of these two important questions. Our main findings indicate the following: (1) Selective depletion but not abolition of SMN protein in spinal motor neuron progenitors that express the transcriptional repressor Olig2 is sufficient to cause an SMA-like phenotype. (2) The selective depletion not only causes early, distal defects of the NMJ but also eventual motor neuron degeneration and consequent muscle atrophy, suggesting that motor neuron pathology in SMA is, at least in part, a cell-autonomous effect of SMN insufficiency. (3) In addition to affecting peripheral neuromuscular synapses, motor neuronal SMN depletion severely perturbs central synaptic integrity. Importantly, this novel finding is also a characteristic of $\Delta 7$ model mice expressing ubiquitously low SMN. (4) Depleting SMN in motor neurons alone is not as deleterious morphologically or phenotypically as depleting the protein ubiquitously, suggesting that other cell types may contribute to SMA pathology. A partial rescue of the SMA phenotype following selective restoration of SMN in neural tissue (Passini et al., 2010) supports this conclusion. (5) Early functional defects of the neuromuscular synapse observed in Olig2-Cre SMA mice likely underlie a corresponding severe motor phenotype. However, functional as well as phenotypic abnormalities in the mutants were attenuated in an age-dependent manner suggestive of a homeostatic compensa-
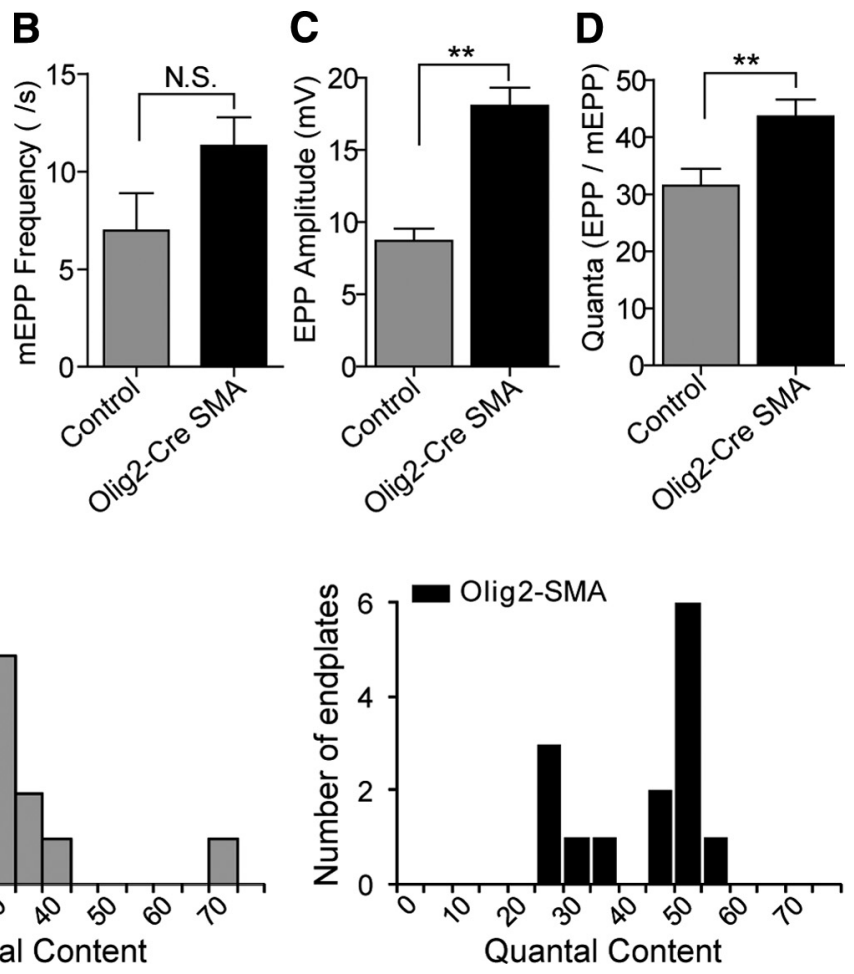

Figure 6. Neuromuscular transmission defects persist at the NMJs of adult Olig2-Cre SMA mice. $\boldsymbol{A}-\boldsymbol{D}$, Transmission parameters stimulus. D, Mean quantal content. No significant difference was detected in mEPP frequency between control and mutant increased at mutant junctions ( ${ }^{* *} p<0.01$, one-way ANOVA). $\boldsymbol{E}$, Histograms of the distributions of quantal contents for contro unctions exhibited a distribution that was more bimodal, indicative of a subpopulation of NMJs at which EPPs are similar in size to

tory mechanism perhaps mediated by non-nervous tissue expressing wild-type levels of the SMN protein. While we cannot exclude the possibility that the attenuated phenotype is due entirely to motor neurons in which Cre-mediated SMN inactivation fails to occur, such a likelihood is sparse considering the small numbers $(<2 \%)$ of these cells as assessed in YFP reporter mice.

Although it is widely recognized that SMA selectively affects spinal motor neurons, it has never been conclusively demonstrated that their loss could be due primarily to a loss of SMN function within them. This hypothesis cannot be tested in the existing cohort of SMA model mice (Park et al., 2010) because they express reduced SMN protein in every cell type, all of which could eventually contribute to the disease phenotype. Studies of purified motor neurons from these mice do not permit an unequivocal answer to the question either, since they are removed from the internal milieu of the intact organism and, in any case, fail to degenerate (Rossoll et al., 2003) as they do in vivo. In the only previous attempt to test whether motor neuron SMN depletion is sufficient to cause SMA, the protein was abolished rather than reduced in the nervous system as it is in the human disease (Frugier et al., 2000). The result of the experiment merely confirmed what had already been established: SMN is required for the survival of all cells. Here, we show for the first time in a mammalian system that depletion, not abolition, of the protein in spinal motor neuron progenitor cells is adequate and sufficient to cause many of the morphologic, functional, and phenotypic characteristics of human SMA. Residual SMN protein in the tar- 
geted spinal motor neurons is expressed from an SMN2 transgene, thus ensuring that the disease condition is faithfully mimicked. While we cannot unambiguously rule out a contributing effect of SMN depletion in oligodendrocytes that also express the Olig2-Cre transgene (Novitch et al., 2001) we used to achieve protein knockdown, it is clear that reduced SMN in nonnervous tissue and even in DRG proprioceptive sensory neurons is not required to cause the neuromuscular phenotype characteristic of human SMA. The effects of reduced SMN in oligodendrocytes will require substituting Olig2-Cre with a different, cell-specific Cre line such as MPB-Cre (where MPB is myelin basic protein) (Niwa-Kawakita et al., 2000).

Two unexpected outcomes of the current study highlight how much remains to be learned about human SMA. First, we have shown that despite the clear SMA-like neuromuscular phenotype following selective motor neuronal SMN depletion, the severity of the disease in Olig2-Cre SMA animals is considerably muted relative to that of $\triangle 7$ SMA mice that express reduced protein in all tissues. Motor dysfunction became apparent in both lines of mutant mice at PND2, but whereas the disease progressed rapidly and became inexorably worse leading to death at $\sim$ PND13 in $\Delta 7$ SMA mutants, the motor phenotype of the Olig2-Cre SMA mutants gradually subsided and, notwithstanding the persistence of morphologic, physiologic, and behavioral abnormalities, the majority of mice entered a relatively stable disease state much akin to the plateau phase of human patients (Sumner, 2007). While such an outcome may be expected if the Olig2-Cre SMA mutants express greater levels of motor neuronal SMN protein than $\triangle 7$ SMA mice, a second plausible explanation for the different phenotypes derives from the expression of wild-type levels of SMN in the non-Olig2-Cre expressing cells of the former transgenic line. Our results indicate that motor neuronal SMN depletion in Olig2-Cre SMA mice is remarkably efficient, and protein levels are equivalent to those in the motor neurons of $\Delta 7$ SMA mutants. One intriguing possibility therefore is that the disparity in overall phenotypes between the two lines of mutant animals lies in the "wildtype" health status of non-nervous tissue in the Olig2-Cre SMA mice. The contributing role of nonmotor neuronal cells in SMA pathology, particularly in light of experimental data in the fruit fly (Chang et al., 2008), continues to be vigorously debated and, even if modest, will only be satisfactorily resolved by selectively and efficiently targeting them in model organisms.

In keeping with the notion of multiple cell types contributing to the SMA phenotype, we were interested to find that Olig2-Cre SMA mice not only stage a significant recovery from the early motor dysfunction that they display but also exhibit a remarkable attenuation of neuromuscular transmission defects between PND8 and PND12. Such a recovery may be rooted in synaptic homeostatic compensatory mechanisms that are activated in response to perturbations in synaptic strength during normal development and in disease (Davis and Bezprozvanny, 2001). For instance at the Drosophila NMJ, reduced muscle innervation eventually results in an increase in quantal size (Davis and Goodman, 1998), and at the neuromuscular synapses of myasthenia gravis patients, altered postsynaptic activity induces an increase in presynaptic neurotransmitter release (Cull-Candy et al., 1980).

An alternative explanation for the recovery of neuromuscular transmission in the Olig2-Cre SMA mutants stems from a rapid sprouting response involving healthy motor neurons in which recombination failed, thus allowing for expression of normal SMN protein. We consider this unlikely for several reasons. First, if healthy motor neurons underlie the recovery, we would have observed some junctions in mutant PND8 muscle that had wild- type quantal content values. In contrast, all values were uniformly reduced (Fig. 5C). Second, if a few motor neurons had sprouted to create large motor units by PND10-12, we would have observed jumps in the twitch and tension values as the stimulus was increased in intensity, but this was not observed. Third, if the recovery of transmission in the semitendinosus and the recovery of motor behavior were because healthy motor neurons had innervated the majority of muscle fibers, one would not expect to find the large number of adult junctions with altered morphology that were observed in the different muscles studied, including the semitendinosus (Fig. 4D, supplemental Fig. S6, available at www. jneurosci.org as supplemental material). Finally, no morphological evidence of sprouting was observed in any of the muscles studied. Our results thus appear more consistent with homeostatic changes, as observed in many systems when transmission is altered, that occurred within mutant SMA motor neurons.

In Drosophila, a number of presynaptic molecules have been shown to mediate the restoration of synaptic strength, most notable among them a subunit of the $\mathrm{Ca}_{\mathrm{V}} 2.1$ (P/Q type) calcium channel. Interestingly, N-type calcium channels, which are expressed embryonically, have been shown to be mislocalized in SMA motor neurons from mice (Jablonka et al., 2007). While many of the presynaptic molecules are thought to be part of a presynaptic cell-autonomous homeostatic compensatory mechanism (Frank et al., 2009; Dickman and Davis, 2009), others, e.g., the glutamate receptor GluRIIA, are thought to be postsynaptically located triggers that initiate a retrograde signal that eventually restores synaptic strength to predetermined levels (Petersen et al., 1997). The precise identity of these signals has eluded researchers so far, but their role in a larger noncell-autonomous compensatory pathway that requires wild-type SMN in muscle cells and serves to attenuate neurotransmission defects at Olig2Cre SMA mutant NMJs holds considerable appeal. Consistent with this notion are results from Ruiz et al. (2010) indicating that quantal content values remain unchanged between PND7 and PND15 in $\Delta 7$ SMA mice wherein all cell types are "mutant." In light of their result and our current study, the role of nonmotor neuronal cells such as muscle and perhaps even terminal Schwann cells in causing the full spectrum of physiological defects is a provocative one. Nevertheless, our findings clearly establish that reduced SMN in these cell types is not a requirement for the SMA phenotype and that a paucity of the protein in motor neurons is sufficient to cause disease.

The emergence of a sensory-motor connectivity defect in $\Delta 7$ and Olig2-Cre SMA mutants was also somewhat unexpected but establishes two important points. First, whereas it may have been argued from an analysis of just the $\Delta 7$ mutants that the defect originates in cells that synapse onto motor neurons, this is improbable. Instead, it is more likely a consequence of events within the motor neurons. Second, one cannot rule out the possibility that reduced sensory-motor connectivity exacerbates the neuromuscular SMA phenotype, but given the persistence of reduced synaptic coverage in adult Olig2-Cre SMA mutants combined with an age-dependent attenuation of both motor dysfunction and NMJ electrophysiology, it is most unlikely that muscle weakness in SMA is entirely caused by this CNS defect. Nevertheless, the reduced numbers of Ia afferents on motor neurons clearly occurs early in the disease, and consequently, it will be interesting to determine first whether the connections are ever made or if the defect reflects inappropriate proprioceptive axonal retraction and second, whether the defect is caused by altered expression of signaling molecules such as Sema3e, which is 
required for afferents to recognize homonymous motor neurons (Pecho-Vrieseling et al., 2009).

In summary, this study provides conclusive evidence that a principal cellular site of action of the SMN protein in determining the SMA phenotype is the motor neuron. Whether the disease phenotype is solely caused by defects in this cell type remains to be precisely determined. Nevertheless, our experiments serve as an additional platform from which one might embark on studies to define possible cellular functions of SMN in diverse cell types. Our report also describes a new line of SMA model mice that could not only serve as a novel tool to tease apart the role of neural versus muscle tissue in the neuromuscular pathology underlying SMA but also as a reagent in drug development efforts, particularly those focused on targeting nervous tissue in milder forms of the disease.

\section{References}

Arber S, Ladle DR, Lin JH, Frank E, Jessell TM (2000) ETS gene Er81 controls the formation of functional connections between group Ia sensory afferents and motor neurons. Cell 101:485-498.

Balice-Gordon RJ, Lichtman JW (1993) In vivo observations of pre- and postsynaptic changes during the transition from multiple to single innervation at developing neuromuscular junctions. J Neurosci 13:834-855.

Bowerman M, Anderson CL, Beauvais A, Boyl PP, Witke W, Kothary R (2009) SMN, profilin IIa and plastin 3: a link between the deregulation of actin dynamics and SMA pathogenesis. Mol Cell Neurosci 42:66-74.

Butchbach ME, Edwards JD, Burghes AH (2007) Abnormal motor phenotype in the SMNDelta7 mouse model of spinal muscular atrophy. Neurobiol Dis 27:207-219.

Cartegni L, Krainer AR (2002) Disruption of an SF2/ASF-dependent exonic splicing enhancer in SMN2 causes spinal muscular atrophy in the absence of SMN1. Nat Genet 30:377-384.

Chang HC, Dimlich DN, Yokokura T, Mukherjee A, Kankel MW, Sen A, Sridhar V, Fulga TA, Hart AC, Van Vactor D, Artavanis-Tsakonas S (2008) Modeling spinal muscular atrophy in Drosophila. PLoS One 3:e3209.

Cifuentes-Diaz C, Frugier T, Tiziano FD, Lacène E, Roblot N, Joshi V, Moreau MH, Melki J (2001) Deletion of murine SMN exon 7 directed to skeletal muscle leads to severe muscular dystrophy. J Cell Biol 152:1107-1114.

Colman H, Nabekura J, Lichtman JW (1997) Alterations in synaptic strength preceding axon withdrawal. Science 275:356-361.

Colquhoun D (1971) Lectures on biostatistics. Oxford: Oxford UP.

Cull-Candy SG, Miledi R, Trautmann A, Uchitel OD (1980) On the release of transmitter at normal, myasthenia gravis and myasthenic syndrome affected human end-plates. J Physiol 299:621-638.

Davis GW, Bezprozvanny I (2001) Maintaining the stability of neural function: a homeostatic hypothesis. Annu Rev Physiol 63:847-869.

Davis GW, Goodman CS (1998) Synapse-specific control of synaptic efficacy at the terminals of a single neuron. Nature 392:82-86.

Dessaud E, Yang LL, Hill K, Cox B, Ulloa F, Ribeiro A, Mynett A, Novitch BG, Briscoe J (2007) Interpretation of the sonic hedgehog morphogen gradient by a temporal adaptation mechanism. Nature 450:717-720.

Dickman DK, Davis GW (2009) The schizophrenia susceptibility gene dysbindin controls synaptic homeostasis. Science 326:1127-1130.

Fischer U, Liu Q, Dreyfuss G (1997) The SMN-SIP1 complex has an essential role in spliceosomal snRNP biogenesis. Cell 90:1023-1029.

Foust KD, Wang X, McGovern VL, Braun L, Bevan AK, Haidet AM, Le TT, Morales PR, Rich MM, Burghes AH, Kaspar BK (2010) Rescue of the spinal muscular atrophy phenotype in a mouse model by early postnatal delivery of SMN. Nat Biotechnol 28:271-274.

Frank CA, Pielage J, Davis GW (2009) A presynaptic homeostatic signaling system composed of the Eph receptor, ephexin, Cdc42, and CaV2.1 calcium channels. Neuron 61:556-569.

Frugier T, Tiziano FD, Cifuentes-Diaz C, Miniou P, Roblot N, Dierich A, Le Meur M, Melki J (2000) Nuclear targeting defect of SMN lacking the C-terminus in a mouse model of spinal muscular atrophy. Hum Mol Genet 9:849-858.

Gabanella F, Butchbach ME, Saieva L, Carissimi C, Burghes AH, Pellizzoni L (2007) Ribonucleoprotein assemble defects correlate with spinal muscu- lar atrophy severity and preferentially affect a subset of spliceosomal snRNPs. PLoS One 2:e921.

Gavrilina TO, McGovern VL, Workman E, Crawford TO, Gogliotti RG, DiDonato CJ, Monani UR, Morris GE, Burghes AH (2008) Neuronal SMN expression corrects spinal muscular atrophy in severe SMA mice while muscle-specific SMN expression has no phenotypic effect. Hum Mol Genet 17:1063-1075.

Jablonka S, Beck M, Lechner BD, Mayer C, Sendtner M (2007) Defective $\mathrm{Ca} 2+$ channel clustering in axon terminals disturbs excitability in motoneurons in spinal muscular atrophy. J Cell Biol 179:139-149.

Kariya S, Park GH, Maeno-Hikichi Y, Leykekhman O, Lutz C, Arkovitz MS, Landmesser LT, Monani UR (2008) Reduced SMN protein impairs maturation of the neuromuscular junctions in mouse models of spinal muscular atrophy. Hum Mol Genet 17:2552-2569.

Kashima T, Manley JL (2003) A negative element in SMN2 exon 7 inhibits splicing in spinal muscular atrophy. Nat Genet 34:460-463.

Kong L, Wang X, Choe DW, Polley M, Burnett BG, Bosch-Marcé M, Griffin JW, Rich MM, Sumner CJ (2009) Impaired synaptic vesicle release and immaturity of neuromuscular junctions in spinal muscular atrophy mice. J Neurosci 29:842-851.

Kwon CH, Zhou J, Li Y, Kim KW, Hensley LL, Baker SJ, Parada LF (2006) Neuron-specific enolase-cre mouse line with cre activity in specific neuronal populations. Genesis 44:130-135.

Le TT, Pham LT, Butchbach ME, Zhang HL, Monani UR, Coovert DD, Gavrilina TO, Xing L, Bassell GJ, Burghes AH (2005) SMNDelta7, the major product of the centromeric survival motor neuron (SMN2) gene, extends survival in mice with spinal muscular atrophy and associates with full-length SMN. Hum Mol Genet 14:845-857.

Lefebvre S, Bürglen L, Reboullet S, Clermont O, Burlet P, Viollet L, Benichou B, Cruaud C, Millasseau P, Zeviani M, Paslier DL, Fresal J, Cohen D, Weissenbach J, Munnich A, Melki J (1995) Identification and characterization of a spinal muscular atrophy-determining gene. Cell 80:155-165.

Liu Q, Fischer U, Wang F, Dreyfuss G (1997) The spinal muscular atrophy disease gene product, SMN, and its associated protein SIP1 are in a complex with spliceosomal snRNP proteins. Cell 90:1013-1021.

Lorson CL, Hahnen E, Androphy EJ, Wirth B (1999) A single nucleotide in the SMN gene regulates splicing and is responsible for spinal muscular atrophy. Proc Natl Acad Sci U S A 96:6307-6311.

McGovern VL, Gavrilina TO, Beattie CE, Burghes AH (2008) Embryonic motor axon development in the severe SMA mouse. Hum Mol Genet 17:2900-2909.

Miniou P, Tiziano D, Frugier T, Roblot N, Le Meur M, Melki J (1999) Gene targeting restricted to mouse striated muscle lineage. Nucleic Acids Res $27: \mathrm{e} 27$.

Monani UR (2005) Spinal muscular atrophy: a deficiency in a ubiquitous protein; a motor neuron-specific disease. Neuron 48:885-896.

Monani UR, Lorson CL, Parsons DW, Prior TW, Androphy EJ, Burghes AH, McPherson JD (1999) A single nucleotide difference that alters splicing patterns distinguishes the SMA gene SMN1 from the copy gene SMN2. Hum Mol Genet 7:1177-1183.

Monani UR, Sendtner M, Coovert DD, Parsons DW, Andreassi C, Le TT, Jablonka S, Schrank B, Rossoll W, Prior TW, Morris GE, Burghes AH (2000) The human centromeric survival motor neuron gene (SMN2) rescues embryonic lethality in $\operatorname{Smn}(-/-)$ mice and results in a mouse with spinal muscular atrophy. Hum Mol Genet 9:333-339.

Monani UR, Pastore MT, Gavrilina TO, Jablonka S, Le TT, Andreassi C, DiCocco JM, Lorson C, Androphy EJ, Sendtner M, Podell M, Burghes AH (2003) A transgene carrying an A2G missense mutation in the SMN gene modulates phenotypic severity in mice with severe (type I) spinal muscular atrophy. J Cell Biol 160:41-52.

Niwa-Kawakita M, Abramowski V, Kalamarides M, Thomas G, Giovannini M (2000) Targeted expression of Cre recombinase to myelinating cells of the central nervous system in transgenic mice. Genesis 26:127-129.

Novitch BG, Chen AI, Jessell TM (2001) Coordinate regulation of motor neuron subtype identity and pan-neuronal properties by the bHLH repressor Olig2. Neuron 31:773-789.

Oliveira AL, Hydling F, Olsson E, Shi T, Edwards RH, Fujiyama F, Kaneko T, Hökfelt T, Cullheim S, Meister B (2003) Cellular localization of three vesicular glutamate transporter mRNAs and proteins in rat spinal cord and dorsal root ganglia. Synapse 50:117-129.

Park G-H, Kariya S, Monani UR (2010) Spinal muscular atrophy: new and 
emerging insights from model mice. Curr Neurol Neurosci Rep 10:108-117.

Passini MA, Bu J, Roskelley EM, Richards AM, Sardi SP, O'Riordan CR, Klinger KW, Shihabuddin LS, Cheng SH (2010) CNS-targeted gene therapy improves survival and motor function in a mouse model of spinal muscular atrophy. J Clin Invest 120:1253-1264.

Pecho-Vrieseling E, Sigrist M, Yoshida Y, Jessell TM, Arber S (2009) Specificity of sensory-motor connections encoded by Sema3e-Plxnd1 recognition. Nature 459:842-846.

Petersen SA, Fetter RD, Noordermeer JN, Goodman CS, DiAntonio A (1997) Genetic analysis of glutamate receptors in Drosophila reveals a retrograde signal regulating presynaptic transmitter release. Neuron 19:1237-1248.

Rafuse VF, Polo-Parada L, Landmesser LT (2000) Structural and functional alterations of neuromuscular junctions in NCAM-deficient mice. J Neurosci 20:6529-6539.

Rossoll W, Jablonka S, Andreassi C, Kröning AK, Karle K, Monani UR, Sendtner M (2003) Smn, the spinal muscular atrophy-determining gene product, modulates axon growth and localization of beta-actin mRNA in growth cones of motoneurons. J Cell Biol 163:801-812.

Ruiz R, Casañas JJ, Torres-Benito L, Cano R, Tabares L (2010) Altered intracellular $\mathrm{Ca}^{2+}$ homeostasis in nerve terminals of severe spinal muscular atrophy mice. J Neurosci 30:849-857.

Schrank B, Götz R, Gunnersen JM, Ure JM, Toyka KV, Smith AG, Sendtner M (1997) Inactivation of the survival motor neuron gene, a candidate gene for human spinal muscular atrophy, leads to massive cell death in early mouse embryos. Proc Natl Acad Sci U S A 94:9920-9925.
Srinivas S, Watanabe T, Lin CS, William CM, Tanabe Y, Jessell TM, Costantini F (2001) Cre reporter strains produced by targeted insertion of EYFP and ECFP into the ROSA26 locus. BMC Dev Biol 1:4.

Sumner CJ (2007) Molecular mechanisms of spinal muscular atrophy. J Child Neurol 22:979-989.

Valori CF, Ning K, Wyles M, Mead RJ, Grierson AJ, Shaw PJ, Azzouz M (2010) Systemic delivery of scAAV9 expressing SMN prolongs survival in a model of spinal muscular atrophy. Sci Transl Med 2:35ra42.

Vitte JM, Davoult B, Roblot N, Mayer M, Joshi V, Courageot S, Tronche F, Vadrot J, Moreau MH, Kemeny F, Melki J (2004) Deletion of murine Smn exon 7 directed to liver leads to severe defect of liver development associated with iron overload. Am J Pathol 165:1731-1741.

Wang X, Li Y, Engisch KL, Nakanishi ST, Dodson SE, Miller GW, Cope TC, Pinter MJ, Rich MM (2005) Activity-dependent presynaptic regulation of quantal size at the mammalian neuromuscular junction in vivo. J Neurosci 25:343-351.

Wang X, Engisch KL, Teichert RW, Olivera BM, Pinter MJ, Rich MM (2006) Prolongation of evoked and spontaneous synaptic currents at the neuromuscular junction after activity blockade is caused by the upregulation of fetal acetylcholine receptors. J Neurosci 26:8983-8987.

Wood SJ, Slater CR (2001) Safety factor at the neuromuscular junction. Prog Neurobiol 64:393-429.

Zhou Q, Wang S, Anderson DJ (2000) Identification of a novel family of oligodendrocyte lineage-specific basic helix-loop-helix transcription factors. Neuron 25:331-343. 